\title{
Aqueous Catalytic Polymerization of Olefins
}

\author{
Stefan Mecking, * Anke Held, and Florian M. Bauers
}

Catalytic conversions in aqueous environments by transition metal complexes have become a well-established field over the past two decades. However, the vast majority of investigations have focussed on small-molecule synthesis. This may appear somewhat surprising as water is a particularly attractive reaction medium, especially for polymerization reactions. For example, aqueous emulsion and suspension polymerization is carried out today on a large scale by noncatalytic free-radical routes. Polymer latices can be obtained as a product, that is, stable aqueous dispersions of polymer particles in the size range of 50 to $1000 \mathrm{~nm}$.
Such latices possess a unique property profile. Amongst other advantages, the use of water as a dispersing medium is particularly environmentally friendly. In comparison to these free-radical reactions, aqueous catalytic polymerizations of olefinic monomers have received less attention. However, considerable advances and an increased awareness of this field have emerged during the past few years. A variety of high molecular weight polymers ranging from amorphous or semicrystalline polyolefins to polar-substituted hydrophilic materials have now been prepared by catalytic polymerization of olefinic monomers in water. Polymer latices based on a number of readily available monomers are accessible and catalytic activities as high as $10^{5}$ turnovers per hour have already been reported. As another example, materials prepared by aqueous catalytic polymerization have been investigated as protein inhibitors. A versatile field spanning colloids, polymer, and coordination chemistry has emerged.

Keywords: colloids • homogeneous catalysis $\cdot$ polymerizations $\cdot$ polymer latex • water chemistry

\section{Introduction}

Aqueous catalytic polymerization may seem like a contradiction at first sight. The high water sensitivity of Ziegler or Phillips catalysts applied commercially for the production of polyolefins is well known. However, water offers a unique combination of properties as a medium for polymerization reactions:

- A high heat capacity, which enables an effective transfer of the heat of polymerization.

- A high polarity that results in a markedly different miscibility with many monomers and polymers compared to organic solvents.

- Surfactants can effectively stabilize dispersions of hydrophopbic polymer particles in water towards aggregation.

- Water is nonflammable and nontoxic.

[*] Dr. S. Mecking, Dr. A. Held, Dipl.-Chem. F. M. Bauers Institut für Makromolekulare Chemie and Freiburger Materialforschungszentrum der Albert-Ludwigs-Universität Freiburg Stefan-Meier-Strasse 31, 79104 Freiburg (Germany) Fax: (+49) 761-203-6319

E-mail: stefan.mecking@makro.uni-freiburg.de
The versatile opportunities resulting can be illustrated by the following noncatalytic free-radical polymerization procedures.

\subsection{Aqueous Free-Radical Polymerization}

Free radical initiated emulsion polymerization is applied today on a multimillion ton scale. ${ }^{[1-4]}$ Originally, emulsion polymerization of styrene and butadiene was developed independently in the United States and in Germany in the 1940s to obtain a substitute for natural rubber during wartime. Today, vinyl acetate, acrylic acid and its esters, butadiene, and styrene comprise the most important monomers for emulsion polymerization.

Polymer latices are obtained as products of emulsion polymerization. A polymer latex is a stable dispersion of polymer particles in the size range of 50 to $1000 \mathrm{~nm}$ in a liquid medium, usually water. Latices are also called polymer dispersions. In such latices, coagulation and precipitation of the polymer particles must be prevented. Stabilization can occur by different mechanisms: by electrostatic stabilization (most often involving ionic surfactants adsorbed to the particle surface), or by steric stabilization (for example, by 
means of water-soluble polymers adsorbed or covalently bound to the particle surface). The mechanism of emulsion polymerization is complex and, despite intense research, many details are still subject to debate. In addition, as a consequence of the different mechanisms of chain growth, chain initiation, and chain transfer in freeradical versus catalytic polymerization, insights gained from the former can not be transferred directly to catalytic polymerizations. Nonetheless, a strongly simplified representation can be useful to illustrate underlying principals.

A typical polymerization mixture initially consists of water, emulsified water-immiscible monomer, surfactant, and a water-soluble initiator. A watersoluble radical, for example, $\mathrm{SO}_{4}{ }^{\cdot-}$ generated from $\mathrm{K}_{2} \mathrm{~S}_{2} \mathrm{O}_{8}$, grows by addition of monomer dissolved in small amounts in the aqueous phase (Scheme 1). The resulting water-soluble oligomeric radical can grow until it reaches a critical chain length at which it becomes insoluble and collapses upon itself ("homogeneous nucleation"). The resulting primary particle is stabilized by adsorption of surfactant, and further polymerization within the particle results in particle growth. Alter- nately, the water-soluble oligomer can enter a surfactant micelle prior to reaching its critical chain length, thus generating a particle ("heterogeneous micellar nucleation"). The emulsified monomer droplets serve as a reservoir for monomer during emulsion polymerization, but as alluded to previously polymerization usually does not occur in these droplets but in the polymer particles to which the monomers diffuses (Scheme 2). (A different situation is encoun-
Stefan Mecking, born October 1966, studied chemistry at RWTH Aachen. In 1994 he received his Ph.D. degree there in the group of W. Keim with a thesis on smallmolecule catalysis by palladium complexes with hemilabile ligands. After an 18-month postdoctoral stay in the group of M. Brookhart (University of North Carolina at Chapel Hill) as a Feodor-Lynen Fellow, he joined the corporate research of Hoechst AG in Frankfurt in 1996 as a research chemist heading a laboratory in the polymers group. In 1998 he moved to Freiburg University, where he is currently working on his habilitation. In addition to aqueous catalytic polymerizations, his research interests include catalytically active colloidal polymer/ metal hybrides. Recently, he received the Eugen-Graetz. Award of Freiburg University in recognition of the latter work.

Anke Held, born in Berlin in 1974, studied chemistry in Marburg. After her diploma thesis with W. Heitz in 1998 she moved to Freiburg to join the group of $S$. Mecking for her dissertation on catalytic aqueous polymerizations by cationic palladium(II) complexes. She recently obtained her Ph.D. degree under the guidance of $R$. Mülhaupt, and now works for Basell in Ludwigshafen (Germany).

Florian M. Bauers, born in Berlin in 1974, studied chemistry in Freiburg. In 2000, he concluded these studies with a diploma thesis on nickel(II)-catalyzed aqueous ethylene polymerization. Since then he has continued this work in his dissertation. In recognition of his outstanding diploma, he was recently awarded the Steinhofer Prize. 
suspension polymerization

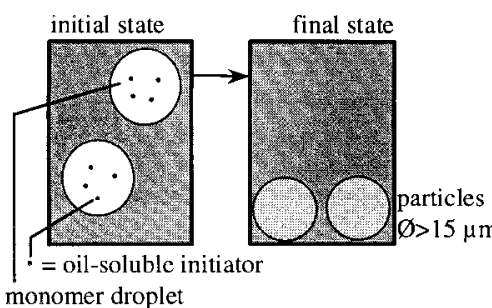

monomer droplet

\section{emulsion polymerization}

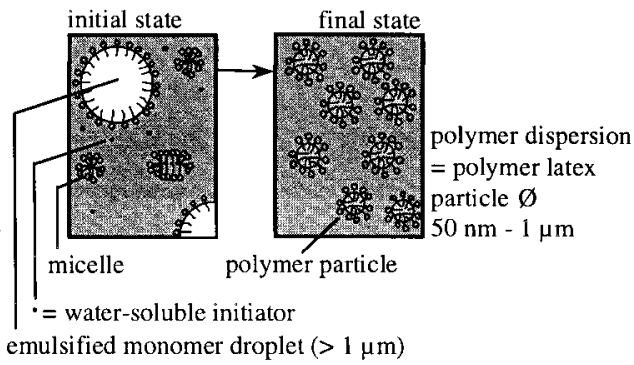

Scheme 2. Schematic representation of free-radical emulsion and suspension polymerization.

tered in the special case of miniemulsion polymerization, see Section 3.) In this respect, the term "emulsion polymerization" can be misleading. In regard to nomenclature, the term "polymerization in emulsion" is frequently used in this review to describe a (catalytic) polymerization carried out under emulsion conditions. This is intended to make no implications about the mechanism of particle formation, which has often not been investigated; also it is not implied whether stable polymer latices were formed or not.

The viscosity of the reaction mixture increases only to a relatively small extent during emulsion polymerization. The viscosity of an aqueous latex is much lower than of a solution of the polymer in an organic solvent. Thus, high polymer yields can be achieved during emulsion polymerization in a given amount of reaction volume. The polymer latices obtained can be precipitated to isolate the polymer, but for many applications they are used as such, for example, in paints and coatings. In such applications film formation is a key step. Evaporation of the dispersing medium results in formation of a continuous polymer film on the substrate. Several million tons of water are evaporated annually by this, and the nonflammability and environmental friendliness of water are particularly advantageous. In addition to existing large-scale applications in paints, coatings, adhesives, paper manufacturing, and other industries, polymer dispersions also possess an interesting potential as submicron-size carrier materials, for example, for biomedical applications ${ }^{[5]}$ or as catalyst supports. ${ }^{[6-9]}$ Polymer latices can also represent the substrates for polymer-analogous modification (namely, synthetic transformations employing a polymer as a substrate). ${ }^{[10,11]}$ The previous considerations show that polymer latices not only represent a convenient opportunity for a polymer supplier to "sell large amounts of water to the customer" ${ }^{[12]}$ along with the polymer, but offer unique advantages regarding applications and the polymerization process.

In suspension polymerization a water-insoluble olefinic monomer is also polymerized. Typically, a mixture of water, water-immiscible monomer, monomer-soluble initiator, and optionally a stabilizer is stirred vigorously. Polymerization occurs in the monomer droplets (Scheme 2). The particles obtained are much larger $(>15 \mu \mathrm{m})$ than in emulsion polymerization, and they do not form stable latices, but instead precipitate during polymerization. For example, the polystyrene beads used for the well-known ion-exchange resins can be prepared by suspension polymerization. ${ }^{[13]}$ In this review, the designation of a catalytic polymerization as "supension-type" should merely indicate a polymerization of a waterinsoluble monomer to a polymer which separates during the polymerization, usually in the absence of any stabilizer.

In dispersion polymerization a soluble monomer is polymerized to an insoluble polymer, which forms a stable latex. With particle sizes of about 1 to $15 \mu \mathrm{m}$, dispersion polymerization can cover the particle size range between emulsion and suspension polymerization.

Aqueous solution polymerization is also well-known, in which a water-soluble monomer is polymerized to a watersoluble polymer. ${ }^{[14]}$ For example, acrylic acid is produced on a large scale by free-radical techniques in this manner. ${ }^{[15]}$ Again, the nonflammability and nontoxicity of water as well as its high heat capacity are advantageous. In some cases performing polymerizations in homogeneous solution can also allow for an increased control of the molecular weight compared to multiphase polymerizations (see Section 6).

\subsection{Transition Metal Catalysis in Aqueous Media}

In contrast to the aforementioned large-scale free-radical polymerizations, transition metal catalyzed coordination polymerization reactions in water have been little investigated. The early transition metal catalysts ${ }^{[16-19]}$ used almost exclusively in commercial catalytic polymerization of olefins are extremely sensitive to moisture. What factors govern the reactivity and stability of a given catalyst towards water? Metal complex catalyzed conversions of olefinic substrates to low molecular weight products or to polymers generally involve organometallics, most often with metal-alkyl bonds, as the active species. Availability of coordination sites for substrate binding is a general prerequisite for catalytic transformations. In regard to catalysis in aqueous media, water can hydrolyze metal-alkyl bonds, block coordination sites by binding as a ligand, and attack coordinated olefin monomers or other ligands. ${ }^{[20]}$ Regarding the former twoperhaps most crucial-aspects, complexes of late transition metals are much less sensitive than early transition metal compounds because of their lower oxophilicity. This stability towards water is illustrated impressively by the large-scale commercial application of the Ruhrchemie-Rhone Poulenc process $^{[21]}$ in which propylene is hydroformylated using a rhodium catalyst in a biphasic aqueous system. In this process a simple separation of the water-soluble catalyst from the apolar products is enabled. A variety of low molecular weight compounds has been prepared by aqueous-phase organometallic catalysis, and such reactions can by no means be regarded as exotic today. By comparison, catalytic polymerizations in water have received little attention. In Cornils and Herrmann's comprehensive book ${ }^{[21]}$ on aqueous-phase organometallic chemistry, the preparation of polymers covers only a minor portion. ${ }^{[22]}$ 
However, carrying out catalytic polymerizations in water is an attractive goal. The previous considerations on free-radical aqueous polymerizations illustrate the unique advantages of water as a reaction medium, and catalytic polymerization offers access to many polymer microstructures which can not be prepared by free-radical techniques. Considerable advances have been achieved over the last few years in the area of aqueous catalytic polymerization. This trend can be related to general advances in late transition metal catalyzed olefin polymerization, an increasing need for environmentally friendly products and processes-and perhaps also simply to a fascination with this topic and the opportunities resulting from the combination of polymer, organometallic, and colloid chemistry. It can be noted that other non-free-radical routes, namely polycondensation ${ }^{[23]}$ and ionic polymerization ${ }^{[24-27]}$ in aqueous emulsion have also received increasing interest recently. Also, metal-mediated reactions such as polymerization by Suzuki coupling in aqueous solution, ${ }^{[28,29]}$ aqueous atom-transfer radical polymerization (ATRP),${ }^{[30-32]}$ and polymerization of acetylenes ${ }^{[33,34]}$ have recently been studied. This paper reviews aqueous catalytic polymerization of olefinic monomers. To exploit its aforementioned unique properties, the presence of water as a major constituent of the reaction medium is usually required, consequently catalytic polymerizations in organic solvents in the presence of only minor amounts of water are excluded. In comparing catalyst activities throughout this review, it should be noted that these data were determined under strongly varying conditions by different authors. Therefore, they should be taken only as an indication of the order of magnitude. The same holds true for polymer molecular weights. Activities are given as turnover per hour $\left(\mathrm{TOh}^{-1}\right.$; $\mathrm{TO}=$ mol substrate converted per mol of metal) so as to enable a comparison of polymerization of different monomers (with different molecular weights) and of catalysts based on different metals.

\section{Copolymerization of Carbon Monoxide with Olefins}

Catalytic olefin-CO copolymerization has found widespread interest as a consequence of the use of cheap starting materials and the materials properties of the copolymers. ${ }^{[35-37]}$ As a result of the mechanism of the reaction, polyketones with a strictly alternating sequence of units derived from olefin and $\mathrm{CO}$ are obtained [Eq. (1)]. An alternating ethylene-CO copolymer melts at $257^{\circ} \mathrm{C}$. Incorporation of propylene

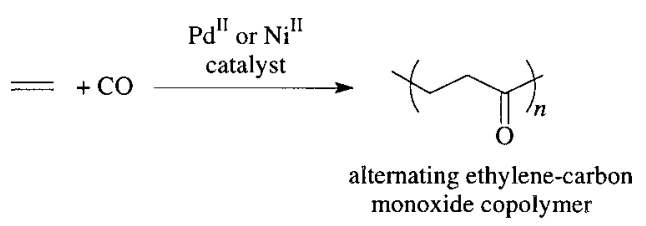

decreases the melting point, thus enabling the processing of the materials (for example, $6 \mathrm{~mol} \%$ propylene: $T_{\mathrm{m}} 220^{\circ} \mathrm{C}$ ). ${ }^{[43]}$ Such semicrystalline ethylene-propylene-carbon monoxide terpolymers have been commercialized by Shell since 1995 as a new engineering thermoplastic under the tradename Carilon, and BP has developed similar materials termed Ketonex. ${ }^{[38,39]}$ However, Shell has recently announced it will abandon this business for undisclosed reasons. ${ }^{[40]}$ The polyketones have a good resistance to hydrocarbon solvents and good abrasion properties. ${ }^{[41]}$ As a drawback, the presence of a large number of carbonyl groups renders the polymers sensitive to UV light; furthermore undesired crosslinking through condensation reactions can occur at high temperatures during processing. These materials are unique in the sense of representing a commercially available olefin polymer with a large number of oxygen-containing polar moieties, prepared by coordination polymerization.

In regard to the catalyst systems used, a major breakthrough has been the finding that catalysts based on cationic palladium(II) complexes with bidentate ligands exhibit substantially increased activities in ethylene-carbon monoxide copolymerization compared to previously known systems. ${ }^{[42,43]}$ In addition to diphosphanes, a variety of bidentate ligands based on nitrogen ${ }^{[44,45]}$ and other donor atoms ${ }^{[46]}$ has been found to be suitable for olefin- $\mathrm{CO}$ copolymerizations. Methanol is typically used as the reaction medium, which demonstrates the stability of these catalysts towards protic media. ${ }^{[4]]}$

The first investigation of a catalytic olefin-CO copolymerization employed water as a reaction medium! In a patent filed in 1948, Reppe and Magin described the reaction of ethylene with carbon monoxide in the presence of an aqueous solution of potassium tetracyanonickel(II)ate at $150^{\circ} \mathrm{C}$ and 150 bar. $^{[48]}$ Along with oligomers of the general structures $\mathrm{H}\left[\mathrm{CH}_{2} \mathrm{CH}_{2} \mathrm{C}(=\mathrm{O})\right]_{n} \mathrm{C}_{2} \mathrm{H}_{5}$ and $\mathrm{H}\left[\mathrm{CH}_{2} \mathrm{CH}_{2} \mathrm{C}(=\mathrm{O})\right]_{n} \mathrm{OH}(n=1$, 2 ), higher molecular weight solid "polyketones" were obtained. This reaction is a very early example, in a general sense, of an aqueous catalytic olefin "polymerization".[49] More recently several reports on ethylene-CO copolymerization in water as a reaction medium have appeared that have been catalyzed by cationic palladium complexes with water-soluble bidentate ligands (for the solubility of the monomers in water see ref. [50]). Sen et al. observed moderate activities of up to about $10^{2} \mathrm{TOh}^{-1}$ in ethylene-CO copolymerization with the sulfonated phosphane- or nitrogenbased ligands $\mathbf{1}$ and $\mathbf{2}$. The reaction conditions are rather mild<smiles>[X]OS(=O)(=O)c1ccc(P(CCCP(c2ccccc2)c2ccc(S(=O)(=O)O[Na])cc2)c2ccc(S(=O)(=O)O[Na])cc2)cc1</smiles>

compared to those used in the work of Reppe and Magin, the reaction being carried out at $50{ }^{\circ} \mathrm{C}$ and 35 bar each of ethylene and $\mathrm{CO}$ (reaction time of $22 \mathrm{~h}$ with the in situ catalyst $\left(\left[\mathrm{Pd}^{\mathrm{II}}\left(\mathrm{NCCH}_{3}\right)_{4}\right]\left(\mathrm{BF}_{4}\right)_{2}\right)$ bidentate ligand). An alternating propylene - CO copolymer with a molecular weight of $1.4 \times$ 
$10^{4} \mathrm{~g} \mathrm{~mol}^{-1}$ (versus polystyrene standards) was also prepared, albeit at lower rates. ${ }^{[51]}$

Sheldon et al. reported significantly higher activities of up to $1.5 \times 10^{4} \mathrm{TOh}^{-1}$ for aqueous ethylene $-\mathrm{CO}$ copolymerization with a very similar catalyst system comprising the same ligand 2. ${ }^{[52]}$ These higher activities, comparable to those observed with 1,3-bis(diphenylphosphanyl)propane (dppp) as the non-sulfonated model for $\mathbf{2}$ in non-aqueous polymerization in methanol, were ascribed to a higher purity of the sulfonated phosphane ligand and the addition of a Brønstedt acid which increased catalyst stability. The molecular weights of the copolymer at $M_{\mathrm{w}} \leq 5 \times 10^{4} \mathrm{~g} \mathrm{~mol}^{-1}$ and $M_{\mathrm{w}} / M_{\mathrm{n}} \approx 2$ were found to be similar to materials obtained in methanol as a non-aqueous reaction medium under otherwise comparable conditions. A high catalyst stability in the aqueous reaction is evidenced by a constant productivity over several hours. $\left.{ }^{[2,}, 53\right]$ A variation of the ligand "backbone" utilizing different chain length $\left(\mathrm{ArP}_{2}-\left(\mathrm{CH}_{2}\right)_{\mathrm{n}}-\mathrm{PAr}_{2}\right.$ with $n=2$ to 5$)$ showed the best results in terms of activity and polymer molecular weight were obtained with $n=3(2) .{ }^{[53]}$ This trend is similar to non-aqueous polymerizations in methanol, that is, apart from solubility issues, no requirements specific to the ligand structure are evident for this particular catalyst system for aqueous polymerizations. Specially designed water-soluble ligands with two sulfonated moieties attached to the $\mathrm{C}_{3}$ ligand backbone (3), ${ }^{[54]}$ or hydroxylated neutral ligands such as $\mathbf{5}^{[55]}$ were found to afford higher activities than 2 .
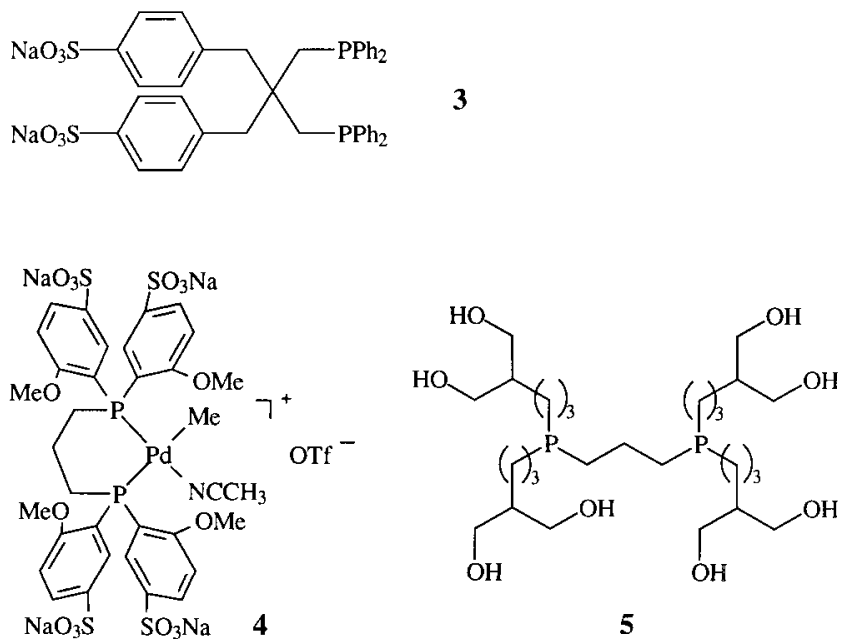

The introduction of methoxy substituents at the ortho position of the aryl rings of a diphosphane-modified cationic palladium catalyst results in markedly increased catalyst performance. ${ }^{[47]}$ Ethylene-CO copolymers with molecular weights of up to $M_{\mathrm{w}} \leq 1.2 \times 10^{5} \mathrm{~g} \mathrm{~mol}^{-1}$ at narrow polydispersities $\left(M_{\mathrm{w}} / M_{\mathrm{n}} \approx 2\right)$ were obtained in the aqueous polymerization with the fully $o$-OMe-substituted analogue of ligand 2. High activities of $6.1 \times 10^{4} \mathrm{TO} \mathrm{h}^{-1}$ have been reported when a well-defined complex 4 of this ligand was used $\left(90^{\circ} \mathrm{C}, 60\right.$ bar ethylene/CO $1 / 1,1 \mathrm{~h}$ reaction time). ${ }^{[56]}$

As alluded to earlier, the properties of ethylene-CO copolymers can be varied by introduction of another olefin as a termonomer, and 1-olefin-CO copolymers are also wellknown. The properties of these copolymers depend strongly on their composition. Thus, the glass transition temperature of
1-olefin-CO copolymers decreases from room temperature to nearly $-60^{\circ} \mathrm{C}$ upon increasing the chain length of the 1-olefin from propylene to 1-dodecene. ${ }^{[37]}$ By contrast to polar ethylene- $\mathrm{CO}$ copolymers, copolymers with higher 1-olefins display a hydrophobic character. Ethylene-1-olefin-CO terpolymers and 1-olefin- $\mathrm{CO}$ copolymers can be prepared in aqueous polymerizations. ${ }^{[51,54,55]}$ Catalysts with entirely alkylsubstituted diphosphane ligands such as $\mathbf{5}$ (by comparison to the phenyl substituents in dppp) are particularly well-suited for 1-olefin copolymerization. ${ }^{[55]}$

In the aforementioned copolymerization reactions, the polyketone was reported to precipitate during the reaction. ${ }^{[53-55]}$ However, in the presence of an emulsifier such as sodium dodecyl sulfate (SDS) and under otherwise suitable conditions, stable polymer latices can be obtained. Such polymerizations can be carried out with water-soluble catalysts based on, for example, ligands of type 5. ${ }^{[57]}$ By using a miniemulsion technique (see Section 3) non-water-soluble catalysts can also be employed. ${ }^{[58]}$ Stable latices of ethylene undec-10-enoic-carbon monoxide terpolymers $\left(M_{\mathrm{w}}=7 \times\right.$ $10^{4} \mathrm{~g} \mathrm{~mol}^{-1}$ versus PMMA standards) and of 1-olefin-CO copolymers $\left(M_{\mathrm{w}}=2 \times 10^{4} \mathrm{~g} \mathrm{~mol}^{-1}\right)$ have been prepared. The carboxylic acid functions as a polymerizable stabilizer. Hereby, modification of the diphosphane ligands to attain water solubility is not necessary, and thus can reduce synthetic effort. With their glass transition occurring below room temperature, 1-olefin-CO copolymers are well suited for film formation. Latices with high solids contents can be prepared.

The mechanism of chain growth by alternating insertion of ethylene and $\mathrm{CO}$ into Pd-acyl and Pd-alkyl species during aqueous polymerization is identical to the well-investigated copolymerization in methanol. A significant difference is represented by hydrolysis as an important chain-transfer step: methanolysis of a Pd-alkyl species affords a $\mathrm{Pd}-\mathrm{OMe}$ species which initiates chain growth during non-aqueous polymerization and results in the formation of a new $\mathrm{CH}_{2} \mathrm{CH}_{2} \mathrm{C}(=\mathrm{O}) \mathrm{OMe}$ end group in the polymer. By contrast, hydrolysis affords a $\mathrm{Pd}-\mathrm{OH}$ species, which reacts with $\mathrm{CO}$ to form a palladium hydride prior to initiation of the next chain (Scheme 3). Therefore, polyketones with two keto end groups are obtained preferentially or exclusively in the aqueous reaction. ${ }^{[52,54,59]}$ The aforementioned reaction can be regarded as a "reactivation" pathway after hydrolysis of a metal-alkyl bond which is specific to aqueous reactions involving CO.

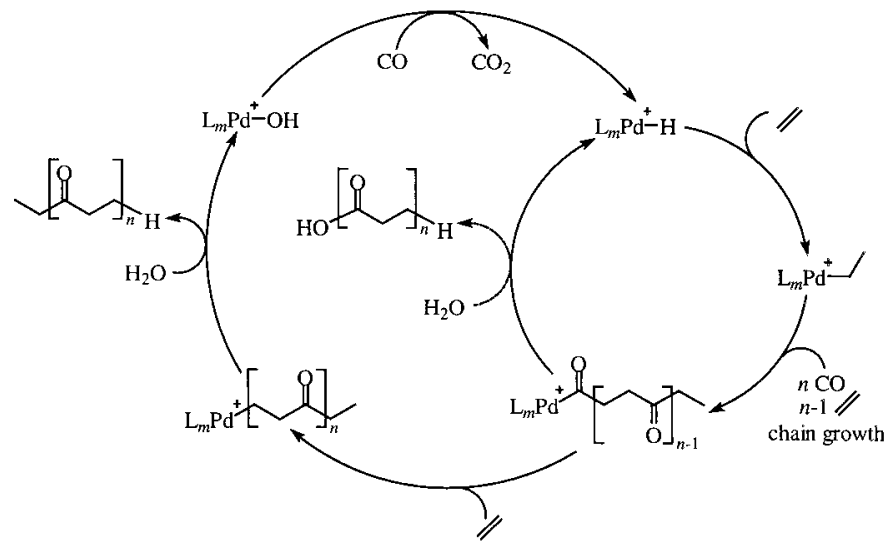

Scheme 3. Mechanism of aqueous ethylene-CO copolymerization. 
From the data available it can be concluded that aqueous ethylene-CO copolymerization can occur at rates similar to the commercially viable process performed in methanol. High molecular weight polyketones can be obtained. Apparent advantages of water as a reaction medium for such polymerizations are its nonflammability and environmental friendliness. The recently demonstrated accessibility of stable latices may enable new applications, which also do not require processing at disadvantageously high temperatures.

\section{Polymerization of Ethylene and 1-Olefins}

Ziegler or Phillips catalysts based on early transition metals ( $\mathrm{Ti}, \mathrm{Zr}, \mathrm{Cr}, \mathrm{V}$ ) are employed in the commercial production of polyolefins. ${ }^{[16-19]}$ However, as a result of their high oxophilicity, such catalysts require strictly anhydrous conditions. In recent years, the discovery of several new types of catalysts for ethylene and 1-olefin polymerization based on late transition metals have spurred a strong interest in this area. ${ }^{[18,60-62]}$ As a consequence of their lower oxophilicity, such catalysts can be much more stable towards polar media.

It can be noted, that latices of low-density polyethylene (LDPE) are prepared as a specialty product by free-radical emulsion polymerization. ${ }^{[63]}$ However, one of the disadvantages this process suffers from is the necessity of working at very high pressures (2000 bar) and a low variability regarding the tailoring of the polymer microstructure.

An ethylene polymerization in water by a well-defined rhodium complex, $\left[\left(\mathrm{N}^{\frown} \mathrm{N} \frown \mathrm{N}\right) \mathrm{RhMe}\left(\mathrm{OH}_{2}\right)(\mathrm{OH})\right]^{+}$, was reported by Flood and co-workers in $1993(\mathrm{~N} \frown \mathrm{N} \frown \mathrm{N}=1,4,7-$ trimethyl-1,4,7-triazacyclononane). Throughout this review, $\mathrm{X} \frown \mathrm{Y}$ or $\mathrm{X} \frown \mathrm{Y} \frown \mathrm{Z}$ denotes a bidentate and a tridentate ligand, respectively, which coordinates through the $\mathrm{X}, \mathrm{Y}$, and $\mathrm{Z}$ atoms). ${ }^{[50,64]}$ A low molecular weight polyethylene was obtained $\left(M_{\mathrm{w}}=5 \times 10^{3} \mathrm{~g} \mathrm{~mol}^{-1}\right)$ at room temperature and 60 bar ethylene after 90 days of reaction. Although the reaction rates of 1 TO per day were extremely low, this finding was an important precedence for aqueous catalytic ethylene polymerization. Interestingly, undesired hydrolysis of the $\mathrm{Rh}$-alkyl bond could be observed at higher temperatures as a reaction competing with chain growth.

In 1995 Brookhart and co-workers reported that cationic diimine-substituted palladium complexes of type 6 can polymerize ethylene to high molecular weight, highly branched material in organic solvents such as dichloromethane. The unique structure of the ethylene homopolymers obtained

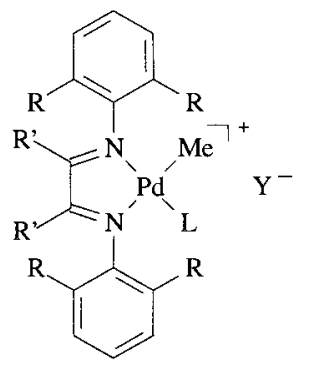

6a:

$\mathrm{R}=\mathrm{R}^{\prime}=\mathrm{Me} ; \mathrm{L}=\mathrm{NCMe}$

$\mathrm{Y}^{-}=\mathrm{SbF}_{6}^{-}$ results from a propensity of the metal centers to "run" along the growing polymer chain between insertions. ${ }^{[65,66]}$ In an extensive patent on these polymerization reactions McLain and co-workers demonstrated with several examples that these can also be carried out in water. ${ }^{[67]}$ Detailed investigations by Mecking and co-workers revealed that the catalyst is remarkably stable in this suspension-type aqueous polymerization. ${ }^{[68,73]}$ Ethylene is polymerized at a steady rate over a time period of $16 \mathrm{~h}$ or longer. Activities of $900 \mathrm{TO} \mathrm{h}^{-1}$, similar to non-aqueous polymerization in dichloromethane, are observed at slightly elevated ethylene pressures of 20 bar with 6a. However, this high stability is attributed to an "encapsulation" of the water-insoluble catalyst in the growing hydrophobic polymer, which protects the catalyst from access of water. Accordingly, aqueous solutions of water-soluble catalysts with sulfonate-substituted diimine ligands are inactive for ethylene polymerization. ${ }^{[69]}$ Mechanistic studies revealed that a complex of type 6 is stable in a watercontaining solution, that is, neither the Pd-Me moiety nor the diimine ligand are hydrolyzed. However, decomposition occurred instantaneously upon addition of ethylene. ${ }^{[68]}$ It is also of interest in the context of aqueous polymerization whether water can compete with the monomer for binding to the metal center and thus block coordination sites necessary for polymerization. Addition of ethylene to the water complex $\left[\left(\mathrm{N}^{\frown} \mathrm{N}\right) \operatorname{PdMe}\left(\mathrm{OH}_{2}\right)\right]^{+}$at $-40^{\circ} \mathrm{C}$ resulted in clean conversion to the known ${ }^{[65]}$ ethylene complex $\left[\left(\mathrm{N}^{\frown} \mathrm{N}\right) \mathrm{PdMe}\left(\mathrm{H}_{2} \mathrm{C}=\mathrm{CH}_{2}\right)\right]^{+} .{ }^{[70,73]}$ This result indicates that water does not have a significant propensity for blocking the coordination sites in this cationic palladium system.

Polymerization by $6 \mathbf{a}$ in aqueous suspension yields a rubbery amorphous solid $\left(M_{\mathrm{w}}=2 \times 10^{5} \mathrm{~g} \mathrm{~mol}^{-1}, M_{\mathrm{w}} / M_{\mathrm{n}}=2\right.$ to 3 , ca. 70 branches per 1000 carbon atoms, $T_{\mathrm{g}}-45^{\circ} \mathrm{C}$ ) while a traditional polymerization in dichloromethane under similar reaction conditions (temperature, ethylene pressure) leads to a highly viscous liquid polyethylene $\left(M_{\mathrm{w}}=3 \times 10^{4} \mathrm{~g} \mathrm{~mol}^{-1}\right.$, ca. 100 branches per 1000 carbon atoms, $\left.T_{\mathrm{g}}-70^{\circ} \mathrm{C}\right)$. However, rather than a conceivable direct interaction of water with the catalyst, this effect appears to be related to the different phases encountered by the catalyst during polymerization (heterogeneous aqueous suspension of polymer encapsulating the catalyst instead of a homogeneous solution) ${ }^{[68]}$ It can be noted that ethylene polymerization by 6 represents a catalytic aqueous synthesis of a hyperbranched polyolefin. ${ }^{[70,71]}$ Polymerization of 1-olefins by catalysts of type $\mathbf{6}$ in aqueous emulsion has been claimed to afford stable latices. ${ }^{[72]}$

In view of many potential applications, synthesis of a largely linear polyethylene with some degree of crystallinity in aqueous emulsion would be of interest. Very recently, Mecking and co-workers and Spitz and co-workers independently reported the nickel(II)-catalyzed polymerization of ethylene to linear material in aqueous emulsion. ${ }^{[73,74]}$ Neutral nickel(II) complexes 7 and 8 (Scheme 4) based on known bidentate $\mathrm{P} \frown \mathrm{O}$ ligands ${ }^{[75-78]}$ were found to be suited as catalyst precursors. Stable latices of low molecular weight polyethylene could be obtained with water-soluble catalyst precursors $7 \mathbf{a}:{ }^{[73,79,80]}$ for example, a dispersion of polyethylene with $M_{\mathrm{w}}=3 \times 10^{3} \mathrm{~g} \mathrm{~mol}^{-1}$ and $M_{\mathrm{w}} / M_{\mathrm{n}}=2-3$ was ob- 


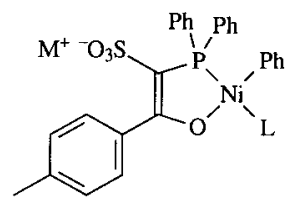

7

$\mathrm{L}=\mathrm{PPh}_{3}$ or pyridine

7a: $\mathrm{M}^{+}=\mathrm{Na}^{+}$(hydrophilic)

7b: $\mathrm{M}^{+}=\mathrm{H}_{33} \mathrm{C}_{16} \mathrm{NMe}_{3}{ }^{+}$(lipophilic) (activation of $\mathrm{PPh}_{3}$ complexes of types 7 or 8

for polymerization by phosphane scavengers)

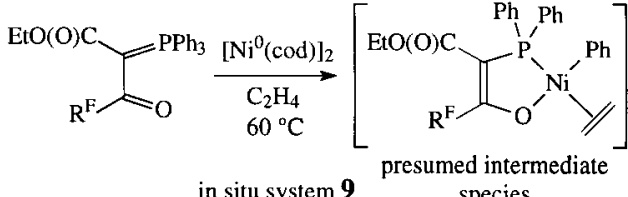

$$
\begin{aligned}
& \mathrm{R}^{\mathrm{F}}=\mathrm{CF}_{3} ; \mathrm{C}_{6} \mathrm{~F}_{5}
\end{aligned}
$$

Scheme 4. Neutral nickel(II) complexes utilized for the polymerization of ethylene in aqueous emulsion.

tained with $10^{3} \mathrm{TOh}^{-1}$ under moderate reaction conditions $\left(70^{\circ} \mathrm{C}, 50\right.$ bar ethylene pressure). The catalysts are stable in the aqueous polymerization for several hours. Significantly higher activities of up to about $3 \times 10^{4} \mathrm{TOh}^{-1}$ were observed with $\mathbf{8}$ in aqueous emulsion, however, the latices prepared with these lipophilic catalyst precursors were reported not to be stable. ${ }^{[74,81]}$ Catalyst activities and polymer molecular weights are reduced in the aqueous polymerizations relative to those observed in traditional polymerization in nonaqueous organic media such as toluene. The lower activities and molecular weights can be related, to a large extent, to a lower rate of chain growth in the aqueous polymerization caused by an insufficient local concentration of ethylene at the catalytically active centers. ${ }^{[79]}$ Good catalyst activities at limited ethylene concentrations can be expected to be advantageous on catalyst performance. ${ }^{[82]}$

Claverie and co-workers have obtained highly active catalysts by introducing electron-withdrawing perfluorinated substituents to the bidentate $\mathrm{P} \frown \mathrm{O}$ ligand $(\mathbf{9}$; Scheme 4$){ }^{[83,84]}$ Low molecular weight linear material $\left(M_{\mathrm{w}}=3 \times 10^{3} \mathrm{~g} \mathrm{~mol}^{-1}\right)$ can be obtained at impressive rates of up to $1.7 \times 10^{5} \mathrm{TO} \mathrm{h}^{-1}$ in aqueous emulsion at ethylene pressures of 25 bar.

High molecular weight polyethylene has been prepared in aqueous polymerizations with a different class of catalysts. ${ }^{[79,88]}$ In traditional polymerization in toluene, suitable representatives of the aforementioned $\mathrm{P} \frown \mathrm{O}$-substituted catalysts and recently reported $\mathrm{N} \frown \mathrm{O}$-substituted salicylaldimine-based catalysts are known to afford polymers of similar maximum $M_{\mathrm{w}}$ values. ${ }^{[62,76,77,85-87]}$ However, by contrast to the previously discussed aqueous polymerizations with $\mathrm{P} \frown \mathrm{O}$ substituted catalysts, the latter type of complexes was found to yield high molecular weight material also in aqueous polymerization. Semicrystalline polyethylenes of $M_{\mathrm{n}} \leq 10^{5} \mathrm{~g} \mathrm{~mol}^{-1}$ with narrow polydispersities $\left(M_{\mathrm{w}} / M_{\mathrm{n}}=2-4\right)$ are accessible in a suspension-type polymerization with precursors $\mathbf{1 0}$. Although these catalysts display a limited stability to water, activities of $3 \times 10^{3} \mathrm{TO} \mathrm{h}^{-1}$ at room temperature are observed. Like the polymers obtained in traditional polymerization in organic solvents, the materials obtained in water with

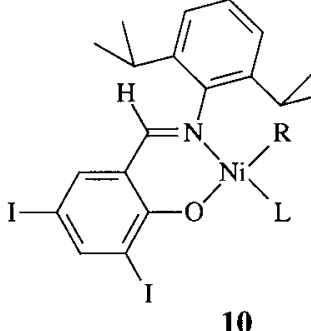

10
$\mathrm{R}=\mathrm{Ph}, \mathrm{L}=\mathrm{PPh}_{3}$

$\mathrm{R}=\mathrm{Me}, \mathrm{L}=$ Pyridin

(activation of the $\mathrm{PPh}_{3}$ complex for as a phosphane scavenger) polymerization by $\left[\mathrm{Rh}\left(\mathrm{H}_{2} \mathrm{C}=\mathrm{CH}_{2}\right)_{2}\right.$ (acac)]

salicylaldimine-based nickel(II) complexes possess a moderate number of methyl branches. Overall, as in the case of the linear polyethylenes obtained with 7-9, the presence of water has no effect on the basic polymer microstructure. Polymer crystallinity can be influenced by employing norbornene as a co-monomer. High molecular weight, amorphous ethylenenorbornene copolymers which form films at room temperature can be obtained in aqueous polymerizations. ${ }^{[79]}$

The synthesis of stable latices requires suitable nucleation of primary particles and subsequent stabilization. Watersoluble initiators are used in classical free-radical emulsion polymerization. Chain growth initially affords water-soluble oligomeric radicals, which can nucleate particles by collapsing upon themselves or by entering a surfactant micelle (see Section 1). Similar considerations appear reasonable for the aforementioned catalytic polymerization to form stable latices with the water-soluble complex $\mathbf{7 a} \cdot{ }^{[73,79]}$ As a different strategy, a very fine initial dispersion of a hydrophobic catalyst precursor can be achieved as a solution in a large number of toluene/hexadecane miniemulsion droplets (diameter ca. $100 \mathrm{~nm}$ ), dispersed in the continuous aqueous phase. ${ }^{[83,88]}$

Miniemulsions ${ }^{[89-91]}$ can be prepared by subjecting a mixture of water, a surfactant, an organic phase, and a so-called hydrophobe to high shear. High shear results in the formation of very small droplets. These are stabilized against Ostwaldripening ${ }^{[92]}$ to larger droplets by the hydrophobe. Miniemulsions can be stable over prolonged periods of time. Freeradical miniemulsion polymerization has been investigated extensively. It should be noted, that the catalytic polymerization reactions of ethylene discussed in the following section differ from typical free-radical polymerization of a preformed miniemulsion of a liquid monomer (Scheme 5). Gaseous ethylene monomer is fed continuously to the reaction mixture after miniemulsification of the catalyst solution. Thus, polymerization of preformed miniemulsion droplets of monomer to particles of the same size, a typical feature of "miniemulsion polymerization", does not apply.

The strategy of using a catalyst miniemulsion for latex synthesis offers two advantages: catalyst precursors do not have to be modified hydrophilically, which often reduces synthetic effort, ${ }^{[83]}$ and somewhat water-sensitive precursors can be applied. ${ }^{[88]}$ Claverie et al. have prepared stable latices of low molecular weight linear polyethylene at high polymerization rates by using miniemulsions of the aforementioned catalysts of type 9. ${ }^{[83]}$ Latices of ethylene copolymers with 1-olefins have also been prepared. ${ }^{[93]}$ In addition to the various attractive aspects of polymerization in emulsion, another significant advantage is relevant in such copolymerizations: in conventional ethylene copolymerizations using 

initiator

b)

$\begin{aligned} & \text { water } \\ & \text { surfactant }\end{aligned}$
hydrophobe
hydrocarbon
shear
solvent
catalyst precursor
catalyst precursor
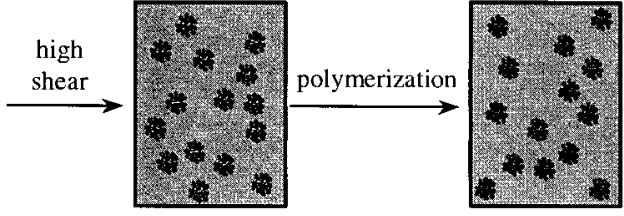

polymer latex particle- $\varnothing$ monomer miniemulsion
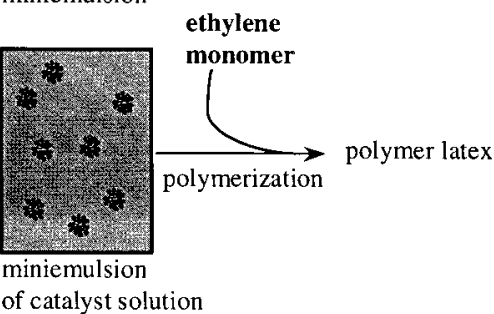

Scheme 5. Comparison of typical free-radical miniemulsion polymerization of a liquid monomer (a) with the particular case of catalytic polymerization of ethylene using a miniemulsion of a catalyst solution (b).

late transition metal catalysts in organic media, the incorporation of 1-olefins is usually low and requires the addition of large amounts of the co-monomer. In emulsions, the high local concentration of the liquid co-monomer in droplets can enable high levels of co-monomer incorporation. Copolymerization of ethylene with comonomers bearing polar, hydrophobic moieties is of strong interest in the context of polymer latices. To date, ethylene copolymerization with undec-10-en1 -ol has been reported briefly. ${ }^{[93]}$

In the aforementioned ethylene polymerizations yielding stable latices low molecular weight polymer was obtained. The synthesis of dispersions of polyolefins with higher molecular weights is necessary to exploit the property profile of polymer latices. Bauers and Mecking have employed miniemulsions of the somewhat water-sensitive catalyst precursor $10(\mathrm{R}=\mathrm{Me}, \mathrm{L}=$ pyridine $)$ for ethylene polymerization. Hereby, stable latices of high molecular weight semicrystalline polyethylene $\left(M_{\mathrm{n}}=10^{5} \mathrm{~g} \mathrm{~mol}^{-1}, M_{\mathrm{w}} / M_{\mathrm{n}}=2-\right.$ 4) could be obtained. ${ }^{[88]}$

The polyethylene latices obtained in the different emulsion polymerization procedures using the various aforementiond nickel(II) complexes display particles with average diameters of 100 to $600 \mathrm{~nm}$. A number of anionic surfactants or neutral stabilizers are suitable, that is, compatible with the catalysts and capable of stabilizing the latex. Solids contents of up to $10 \%$ have been reported to date. A typical transmission electron microscopy (TEM) image is shown in Figure 1. By comparison to the smooth, spherical latex particles of amorphous polystyrene, as an example of a well-studied hydrocarbon polymer prepared by free-radical emulsion polymerization, the ruggedness of the particles shown can be rationalized by their high degree of crystallinity.

Very recently, an aqueous olefin polymerization using an early transition metal catalyst has also been reported. ${ }^{[94]} \mathrm{A}$ solution of styrene in toluene is prepolymerized briefly by a catalyst prepared by the combination of $\left[\left(\mathrm{C}_{5} \mathrm{Me}_{5}\right) \mathrm{Ti}(\mathrm{OMe})_{3}\right]$ with a borate and an alkylaluminum compound as activators. The reaction mixture is then emulsified in water, where further polymerization occurs to form syndiotactic polystyrene stereoselectively. It is assumed that the catalyst is contained in emulsified droplets and is thereby protected from the access of water, with the formation of a crystalline polymer enhancing this effect. Cationic or neutral surfactants were found to be suited, whereas anionic surfactants deactivated the catalyst. The crystalline polystyrene formed was reported to precipitate from the reaction mixture as relatively large particles of $500 \mu \mathrm{m}$.

A number of catalytic aqueous ethylene polymerizations have been reported very recently. A particularly interesting aspect is the successful synthesis of latices of largely linear polyethylenes. Copolymerization with various olefinic monomers enables a control of the polymer crystallinity. High catalyst activities have already been achieved in the synthesis of latices of low molecular weight material. Such polymerizations can be of interest as a

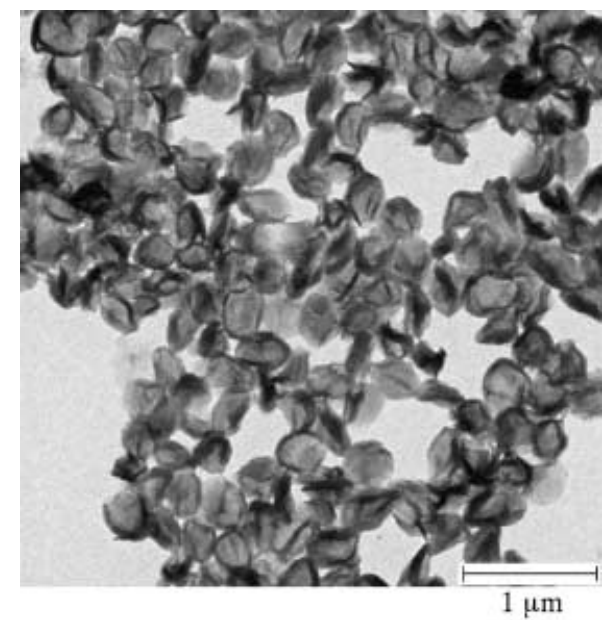

Figure 1. TEM micrograph of polyethylene latex particles prepared by catalytic polymerization $\left(M_{\mathrm{w}}=2.1 \times 10^{5} \mathrm{~g} \mathrm{~mol}^{-1}, M_{\mathrm{w}} / M_{\mathrm{n}}=2.2 ;\right.$ crystallinity $54 \%$; catalyst precursor $10(\mathrm{R}=\mathrm{Me}, \mathrm{L}=$ pyridine $)) .{ }^{[88]}$

convenient direct route to wax dispersions. The accessibility of latices of high molecular weight polyethylene has also been demonstrated. Further improvements of catalyst activities are clearly an important aim in this field. The role of small amounts of added organic solvents, for example, in the miniemulsion technique, on catalyst performance remains to be clarified. The aforementioned activities reported to date for aqueous ethylene polymerization $\left(10^{5} \mathrm{TO} \mathrm{h}^{-1}\right)$ are lower than those of metallocenes as single-site catalysts used for the commercial production of polyolefins $\left(>10^{7} \mathrm{TOh}^{-1}\right) \cdot{ }^{[95]}$ Ziegler catalysts, including metallocenes, have been improved continuously with enormous efforts over the past 50 years. In view of potential applications, it is debatable whether catalyst activities in aqueous polymerizations must rival those of today's polyolefin production, or whether restrictions are not quite as stringent as in today's polyolefin industry. As an example of properties interesting for potential applications, polyolefins contain a negligible portion of double bonds compared to styrene - butadiene copolymers, a hydrocarbonpolymer currently prepared by free-radical emulsion poly- 
merization on a large scale. This lower level of double bonds can result in a considerably higher stability of polymer films formed from polyolefin latices towards UV light and air.

\section{Polymerization of Conjugated Dienes}

Free-radical polymerization of butadiene in aqueous emulsion is performed on a large scale. Butadiene-styrene copolymer latices are employed, for example, in paper treatment. ${ }^{[2]}$ Transition metal catalyzed polymerization of dienes in non-aqueous media is equally important. cis-1,4Polybutadiene rubbers are produced with Ziegler-type catalysts based on titanium, cobalt, nickel, or neodymium in solution processes with aromatic hydrocarbon solvents. ${ }^{[106]}$

Polymerization of butadiene catalyzed by rhodium salts in water as a reaction medium was already reported in the 1960s by Rinehart et al. and Canale and co-workers. By utilizing $\mathrm{Rh}^{\mathrm{III}} \mathrm{Cl}_{3} \cdot 3 \mathrm{H}_{2} \mathrm{O}$ as a catalyst precursor butadiene is polymerized stereoselectively in aqueous emulsion to semicrystalline trans-1,4-polybutadiene exclusively [Eq. (2); >99\% trans]. ${ }^{[0,96,97]}$ By comparison, free-radical polymeriza-

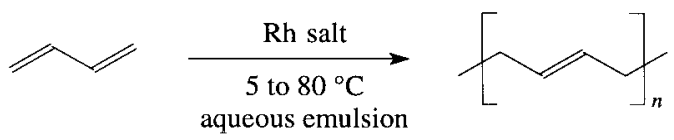

tion of butadiene in aqueous emulsion typically yields polymers with $60 \%$ trans-incorporated units under similar conditions. ${ }^{[98]}$ Polymerization of butadiene in water as a reaction medium by salts of late transition metals other than rhodium was reported to yield polybutadienes of other microstructures, however, the data provided is very limited. ${ }^{[97]}$

Polymer molecular weights of $2.6 \times 10^{4} \mathrm{~g} \mathrm{~mol}^{-1}$ were determined by light scattering measurements. ${ }^{[97]}$ The catalyst activity was virtually constant over $30 \mathrm{~h}$ at $50^{\circ} \mathrm{C}$, which demonstrates there is a remarkably high stability of the catalyst in the aqueous polymerization. ${ }^{[99]}$ Anionic emulsifiers, namely SDS or alkylbenzene sulfonates, were found to be suitable. ${ }^{[96,100]}$ On the basis of polymer microstructure and comparative experiments with radical inhibitors, a coordination polymerization mechanism was suggested. A free-radical polymerization mechanism can be excluded. Rhodium(I) species, formed by the reduction of the $\mathrm{Rh}^{\text {III }}$ salts used as the catalyst precursors by the butadiene monomer, have been suggested as the active species. In agreement with this, $\mathrm{Rh}^{\mathrm{I}}$ complexes such as $\left[\mathrm{Rh}_{2} \mathrm{Cl}_{2}\left(\mathrm{C}_{4} \mathrm{H}_{6}\right)_{3}\right]$ are also active catalysts with moderate activities of up to about $2 \times 10^{3} \mathrm{TOh}^{-1}$ (with formic acid as a co-catalyst). ${ }^{[101,102]}$ In contrast to industrially important free-radical copolymerization, styrene is not incorporated in the rhodium-catalyzed butadiene polymerization. ${ }^{[103]}$ The rhodium catalyst is also inactive towards isoprene, ${ }^{[101,103]}$ whereas other authors have reported polymerization of cis- or trans-1,3-pentadiene in aqueous emulsion. ${ }^{[104]}$ Only limited data is available regarding the stability and other properties of the polymer dispersions obtained. Precipitation of considerable portions of the polymer has been mentioned at high conversions in the polymerization of butadiene..$^{[99,105]}$
The growing polymer chain in the polymerization of dienes by late transition metal complexes is generally assumed to coordinate to the metal center in a $\eta^{3}$-allyl fashion $(\mathbf{A}){ }^{[106]}$ Allyl complexes are generally considered to be quite stable

$$
\left\langle\left(\mathrm{ML}_{n} \text { (butadiene) } \mathrm{A}, \mathrm{R}=\right.\right.\text { growing polymer chain }
$$

compared to other organometallic compounds, particularly to alkyl compounds. ${ }^{[107]}$ Thus, it is perhaps not surprising that the coordination polymerizations of dienes in water were discovered relatively early on.

Polymerization of butadiene by modified cobalt catalysts, such as the in situ system $\left[\mathrm{Co}^{\text {III }}(\mathrm{acac})_{3}\right] / \mathrm{AlEt}_{3} / \mathrm{H}_{2} \mathrm{O} / \mathrm{CS}_{2}$ $($ acac $=$ acetylacetonate $)$, can yield highly crystalline syndiotactic 1,2-polybutadiene $\left(T_{\mathrm{m}}=205^{\circ} \mathrm{C}\right) .{ }^{[108]}$ The high stereoselectivity of these catalysts has been ascribed to coordination of carbon disulfide as a ligand to the metal center. ${ }^{[109]}$ Such stereospecific polymerizations can be carried out in aqueous emulsion, ${ }^{[110-112]}$ and polymer latices can be obtained [Eq. (3)]. ${ }^{[111]}$ A "prepolymerization" with a small portion of

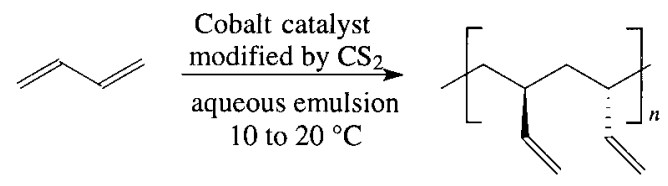

butadiene monomer in the presence of only trace amounts of water is required. A solution of this "prepolymerized" catalyst mixture in a hydrocarbon is subsequently dispersed in water together with further butadiene, and the polymerization then proceeds. It has been speculated that the catalytically active species is shielded from the access of water by the polymer formed during the prepolymerization. ${ }^{[110]}$

The aforementioned catalytic polymerizations offer access to special polymer microstructures in aqueous emulsion. However, it must be noted that particularly the expensive rhodium complexes used in the pioneering work display only moderate activities. Latices of butadiene-(CO) polymers suited for a variety of applications are already prepared conveniently on a large scale by established free-radical routes.

\section{Vinylic Polymerization of Cyclic Olefins}

The vinylic polymerization of cyclic olefins, in which the ring structure is left intact, has been less thoroughly investigated than ROMP (see Section 6). An early example of an aqueous polymerization is provided by the rhodium-catalyzed polymerization of cyclobutene in emulsion. Under similar conditions as those described by Rinehart et al. for butadiene polymerization (Section 4), Natta et al. obtained a crystalline, highly stereoregular polymer with low conversions [Eq. (4)]. ${ }^{[113]}$ Ring opening is only a minor side reaction compared with ruthenium-catalyzed aqueous ROMP of cyclobutene (Section 6). 


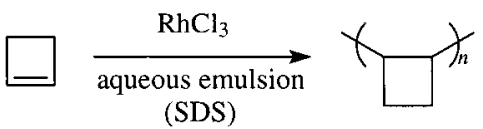

Vinylic polymerization of norbornene (the most common monomer) can be catalyzed in non-aqueous media by complexes of various metals such as titanium, ${ }^{[114]}$ zirconium, ${ }^{[115]}$ chromium, ${ }^{[116]}$ cobalt $^{[117]}$ nickel(II) ${ }^{[118,119]}$ or palladiu$\mathrm{m}(\mathrm{II}) .{ }^{[120-123]}$ Late transition metals can display high activities when, for example, well-defined weakly coordinated nickel(II) complexes $^{[118]}$ are used as catalyst precursors or with methylaluminoxane (MAO)-activated nickel(II) and palladium(II) catalysts. ${ }^{[124-126]}$ The resulting polynorbornenes are amorphous hydrocarbon materials of varying tacticity (depending on the catalyst). They can display high thermal stability and a low dielectric constant. Polynorbornene and functionalized derivatives have been marketed under the brand-name Avatrel as materials for electronics applications. ${ }^{[127,128]}$

It should be noted, that the reactivity of 2,3-substituted norbornenes, which are often employed as monomers in aqueous polymerizations, can be strongly affected by its configuration (exo/endo). The configuration of the monomers utilized has not always been specified in the literature, which can complicate a detailed comparison of results by different authors. Also, it must be noted that characterization of unfunctionalized polynorbornene obtained with palladium catalysts is often complicated by its notorious insolubility in organic solvents. ${ }^{[129]}$ The tolerance of norbornene polymerization with $\left[\mathrm{Pd}\left(\mathrm{NCCH}_{3}\right)_{4}\right]\left(\mathrm{BF}_{4}\right)_{2}$ as an initiator towards added amounts of water (1000 equivalents with respect to Pd) has been described by Mehler and Risse. ${ }^{[122]}$

A polymerization of norbornene affording an aqueous latex was reported in 1993 by Perez and co-workers. Norbornene $\left(T_{\mathrm{m}}=44^{\circ} \mathrm{C}\right)$ was treated in aqueous emulsion at $70^{\circ} \mathrm{C}$ with SDS as an emulsifier and $\mathrm{PdCl}_{2}$ as a catalyst precursor [Eq. (5)]. ${ }^{[130,131]}$ With moderate catalyst activities of $70 \mathrm{TOh}^{-1}$,

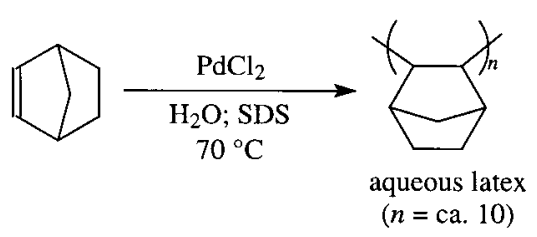

a stable latex consisting of low molecular weight oligomeric material $\left(\mathrm{DP}_{\mathrm{n}} \approx 10, \mathrm{DP}_{\mathrm{n}}=\right.$ degree of polymerization $)$ was obtained. Interestingly, very small latex particles of 10 to $20 \mathrm{~nm}$ diameter were reported. In well-known free-radical polymerization of olefinic monomers, such small particles are only obtained by microemulsion polymerization. $\mathrm{PdCl}_{2}$ is slightly water-soluble, and the authors have reasoned that polymerization occurs preferentially at the interface between the water and monomer droplets (although the catalytically active species has not been identified unambiguously). At the same time, Safir and Novak reported the polymerization of polar substituted norbornadienes $\mathbf{1 1}$ in aqueous emulsion with $\mathrm{PdCl}_{2}$ [Eq. (6)].[132]

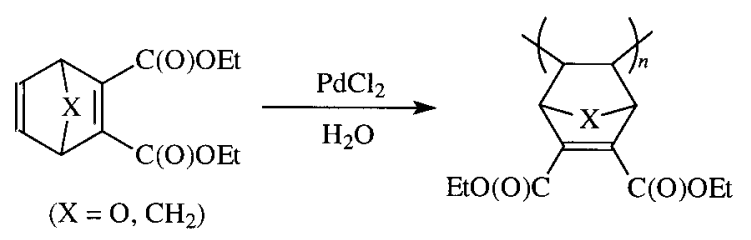

$11 \mathbf{a}$

A few years later Perez and co-workers polymerized a water-soluble norborn-5-en-2-yl-substituted gluconamide (11b) and a lactbionamide (11c) with water-soluble

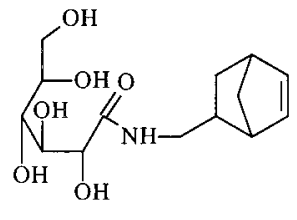

$11 b$

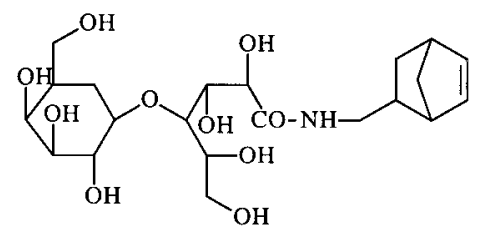

11c<smiles>NS(=O)(=O)c1cccc(P(c2cccc(S(N)(=O)=O)c2)c2cccc(S(=O)(=O)O[Na])c2)c1</smiles>

$\left[\mathrm{PdCl}_{2}\left(\mathrm{NaTPPTS}_{2}\right]\right.$ in aqueous solution. ${ }^{[133]}$ Oligomers with a degree of polymerization $\mathrm{DP}=17$ and 12 , respectively, were obtained in a vinylic polymerization with moderate efficiency (86 TO during an entire polymerization run). The watersoluble oligomers form aggregates in solution. Like their analogues formed by ROMP, such glycopolymers have been suggested as therapeutic agents. A cationic polyelectrolyte with a degree of polymerization DP of 94 was obtained by polymerization of [5-(methyleneammonium)norborn-2-ene] chloride with $\mathrm{PdCl}_{2}$ in aqueous solution. Cell transfection by DNA complexes of this polyelectrolyte has been investigated. ${ }^{[134]}$

Polymerization of butylnorbornene by a catalyst system containing one equivalent of the water-soluble phosphane ligand NaTPPTS, [\{(allyl)Pd( $\left.\mu-\mathrm{Cl})\}_{2}\right] / \mathrm{NaTPPTS} / \mathrm{Li}\left[\mathrm{B}\left(\mathrm{C}_{6} \mathrm{~F}_{5}\right)_{4}\right]$, has also been described. A high activity of $4.5 \times 10^{4} \mathrm{TOh}^{-1}$ has been claimed for this aqueous suspension-type polymerization in a patent. ${ }^{[135]}$ This may be taken as an indication that substantially higher productivities can be achieved in vinylic aqueous polymerization of norbornene monomers compared to the moderate efficiencies reported to date.

\section{Ring-Opening Metathesis Polymerization}

Ring-opening metathesis polymerization (ROMP) of cyclic olefins can be carried out with a variety of catalysts based on different metals, ${ }^{[136,137]}$ with molybdenum, tungsten, and ruthenium catalysts being employed most often. In regard to the mechanism of olefin metathesis, ${ }^{[138]}$ it is generally agreed 
upon that metal alkylidenes represent the active species (Scheme 6). Polymers prepared by (non-aqueous) ROMP of olefinic monomers such as norbornene, dicyclopentadiene, and cyclooctene are applied commercially. ${ }^{[139]}$ In most commercial processes, and also in much academic research, poorly defined in situ catalysts have been applied. The advent of catalytically active metal alkylidenes as well-defined precursors in the 1980s was a strong thrust for the metathesis of olefins as a synthetic method in general, and for aqueous ROMP in particular. [136, 140-143]

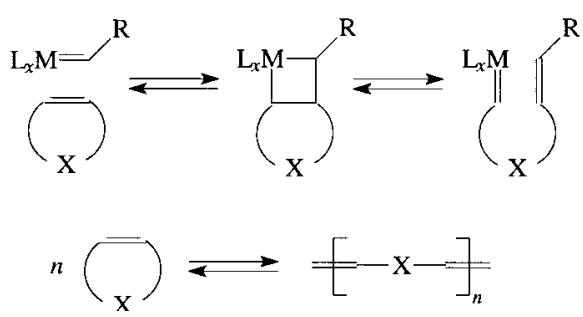

Scheme 6. Mechanism (top) and overall reaction (bottom) of chain growth in ROMP.

An early example of aqueous ROMP was provided by Natta et al. with polymerization of cyclobutene and 3-methylcyclobutene using $\mathrm{RuCl}_{3}$ as a catalyst precursor. ${ }^{[144]}$ Low molecular weight stereo-irregular oils were formed with low activities of about 15 TO. Polymerization occurs exclusively by ring opening [Eq. (7)].

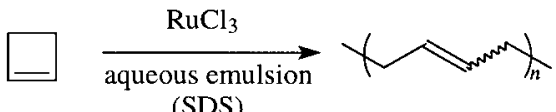

(SDS)

Rinehart et al. have reported ROMP of norbornene and of 2-functionalized norborn-5-enes with polar ester moieties in aqueous emulsion with moderate activities. Iridium(III) or iridium(Iv) salts in combination with a reducing agent, or $\mathrm{Ir}^{\mathrm{I}}-$ olefin complexes were employed as catalyst precursors. Norbornadiene and dicyclopentadiene were also polymerized, with only one double bond reacting. ${ }^{[101,145]}$

In 1988, Grubbs and Novak reported ROMP of aqueous solutions of functionalized 7-oxanorbornenes $\mathbf{1 2}$ and $\mathbf{1 3}$ using $\mathrm{RuCl}_{3}$ or $\left[\mathrm{Ru}^{\mathrm{II}}\left(\mathrm{OH}_{2}\right)_{6}\right](\mathrm{OTs})_{2}(\mathrm{OTs}=$ toluene-4-sulfanoate $)$ as catalyst precursors. ${ }^{[146]}$ Polymer molecular weights were found to be higher at more narrow molecular weight distributions $\left(M_{\mathrm{w}}=1.3 \times 10^{6} \mathrm{~g} \mathrm{~mol}^{-1} ; M_{\mathrm{w}} / M_{\mathrm{n}} 1.2\right.$ for 13) than those obtained by polymerization in organic solutions. The high catalyst stability towards water is underlined by the possibility of multiple recycling of the catalyst solutions. Advantageously, an initiation period of the catalyst prior to the onset of polymerization is reduced in the presence of water. An analysis by Feast and Harrison of the polymers resulting from
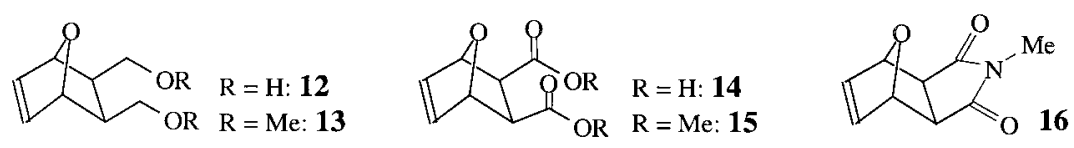

(exo,exo isomers in all cases) aqueous ROMP of $\mathbf{1 3}$ with $\mathrm{RuCl}_{3}$ and $\mathrm{OsCl}_{3}$ revealed these materials to be atactic with a varying ratio of cis to trans double bonds in the backbone. ${ }^{[147,148]}$ As a general feature, trans linkages are usually obtained preferentially in ROMP of norbornene using $\mathrm{RuCl}_{3}$ as a catalyst precursor. A number of other functionalized norbornenes (14-16) have been polymerized to high molecular weight polymer in aqueous media. ${ }^{[14-152]}$ Although this issue was only mentioned as an aside, probably in all these cases the catalyst precursor and the monomer (12-16) initially formed a homogeneous solution, and the water-insoluble polymer precipitated during the polymerization reaction when a largely aqueous reaction medium was employed. Acyclic olefins can function as chaintransfer agents to regulate molecular weights..$^{[147,149,153]}$ The analysis of the resulting oligomeric products supported the presence of ruthenium alkylidene species. ${ }^{[153]}$ Also in accordance with intermediacy of a ruthenium alkylidene species in the aqueous polymerization, the addition of ethyl diazoacetate as a carbene source to $\left[\mathrm{Ru}^{\mathrm{II}}\left(\mathrm{OH}_{2}\right)_{6}\right](\mathrm{OTs})_{2}$ enabled ROMP of less reactive low-strain cyclic olefins such as cyclooctene. ${ }^{[154]}$

A significant advance was achieved by the utilization of isolated ruthenium carbene complexes as catalyst precursors. Solutions of complex 17 a in organic media were found to be stable to added amounts of water, thus indicating that such

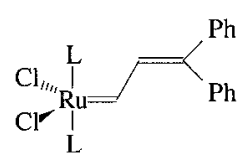

$$
\mathrm{L}=\mathrm{PPh}_{3}: \mathbf{1 7} \mathbf{a}
$$$$
\mathrm{L}=\mathrm{PCy}_{3}: \mathbf{1 7 b}
$$

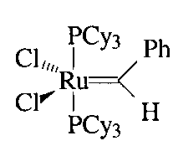

18 alkylidenes were suitable as catalyst precursors for aqueous reactions. ${ }^{[155]}$ In subsequent work, rather than the vinylsubstituted carbenes of type 17, carbene complexes of type $\mathbf{1 8}$ were employed most often. They are easily accessible by employing diazoalkanes as the reagents for the generation of the metal-alkylidene moiety and they represent more efficient initiators. ${ }^{[156,157]}$ Complexes of the bulky trialkylphosphane $\mathrm{PCy}_{3}(\mathrm{Cy}=$ cyclohexyl $)$ were found to generally display higher activities in ROMP than their $\mathrm{PPh}_{3}$ analogues. Compounds $\mathbf{1 7 b}$ and $\mathbf{1 8}$ are now available commercially.

As a result of the water-insolubility of these metal carbenes, aqueous polymerizations represent heterogeneous multiphase mixtures. Investigation of ROMP of the hydrophilic monomer $\mathbf{1 6}$ or of a hydrophobic norbornene in aqueous emulsion (catalyst precursor $\mathbf{1 7} \mathbf{b}$ or $\mathbf{1 8}$ added as a solution in dichloromethane) or suspension demonstrated that the polymerization can occur in a living fashion. For example, at a monomer to initiator ratio $\mathbf{1 6} / \mathbf{1 8}=100 / 1$ with $78 \%$ yield of poly-16 with $M_{\mathrm{w}} / M_{\mathrm{n}} 1.07$ (versus polystyrene standards) was obtained. ${ }^{[158]}$ The cationic dodecyltrimethylammonium bromide (DTAB) was used preferentially as a surfactant for polymerization in emulsion. Block copolymers of narrow molecular weight distribution are 
also accessible. Living polymerization can be carried out in aqueous solution, without the addition of surfactants or organic cosolvents, by using water-soluble carbene complexes of type 19 and water-soluble monomers 20. ${ }^{[159]}$ Interestingly, addition of small amounts of acid (up to 1 equiv $\mathrm{DCl}$ ) is advantageous for catalyst performance. One reason is that

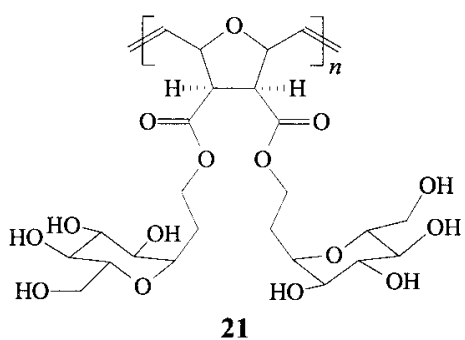

dene complexes $\mathbf{1 7}$ or $\mathbf{1 8}$ as well-defined catalyst precursors for the polymerization of norbornene derivatives with unprotected carbohydrate residues is again complicated by the water-insolubility of these ruthenium carbenes. Polymerization can be carried out in emulsion (water/dichloromethane/surfac$\operatorname{tant}) \cdot{ }^{[166,167]}$ In ROMP of a carboximide-functionalized norbornene (see 16) N-substituted with a carbohydrate

small amounts of hydroxide ions, detrimental for catalyst stability, are eliminated. The acid was found to react with complex 19a to afford a monophosphane complex and the phosphonium salt of the ligand, which means that remarkably the metal-alkylidene moiety does not react with the acid. The high stability of ruthenium-alkylidene species towards water during the polymerization reaction was confirmed by NMR spectroscopic analysis.

ROMP of norbornene in aqueous emulsion by employing ruthenium(Iv) complexes ${ }^{[160]}$ with bis(allyl) ligands such as the water-soluble $\left[\left(\eta^{3}: \eta^{3}-\mathrm{C}_{10} \mathrm{H}_{16}\right) \mathrm{Ru}\left(\mathrm{OH}_{2}\right)(\mathrm{OAc})\right] \mathrm{BF}_{4}$ as catalyst precursors has been reported by Wache. ${ }^{[161]}$ High molecular weight polymer with an unusually high cis content was obtained with rates of $100 \mathrm{TOh}^{-1}$. ROMP of deltacyclene, a more peculiar monomer, by $\mathrm{RuCl}_{3}$ in aqueous suspension has been reported to afford high molecular weight stereo-irregular polymer. ${ }^{[162]}$

The synthesis of neoglycopolymers by ROMP has been investigated extensively by Kiessling et al. (the term neoglycopolymer refers to a synthetic, non-natural polymer bearing carbohydrate moieties). ${ }^{[163]}$ In comparison to other synthetic methods, ROMP can offer the potential for good functional group tolerance together with the possibility of molecular weight control. Carbohydrate-substituted monomers can be employed without protection of the hydroxy groups, thus reducing the synthetic effort and also preventing problems frequently encountered in deprotection steps. As the monomers and also the desired polymers are highly hydrophilic and water soluble, aqueous ROMP can offer the advantage of a homogeneous reaction, which is beneficial for molecular weight control and catalyst efficiency. ROMP of 7-oxanorbornenes substituted with glucose or mannose moieties bound through $\mathrm{C}^{-}$or $\mathrm{O}^{-}$-glycosidic linkages afforded neoglycopolymers, such as $\mathbf{2 1} .^{[164,165]}$

The reaction can be performed using an aqueous solution of $\mathrm{RuCl}_{3}$ and monomer to afford the water-soluble polymers. Relative molecular weights of about $10^{6}$ (by comparison to dextran standards) were estimated. The polymers contain cis as well as trans double bonds in roughly equal amounts in the backbone which can be reduced to yield a saturated polymer by employing hydrazine reduction. ${ }^{[165]}$ Utilization of alkylimoiety, increasing average degrees of polymerization in the range of $\mathrm{DP}_{\mathrm{n}}=10$ to 143 were observed with increasing monomer to catalyst ratio (18 as a catalyst precursor). This observation indicates a certain degree of control over the molecular weight, although molecular weight distributions were not reported. ${ }^{[167]}$ The erythrocyte-agglutinating activity of the protein concanavalin A can be inhibited by the binding of carbohydrates. Structure/activity relationship have been investigated using the carbohydrate-substituted ROMP polymers with systematically varied structures as multivalent inhibitors. ${ }^{[164-166,168]}$

It should be noted that removal of metal residues from the unsaturated polymers generated by ROMP is a ubiquitous issue ${ }^{[165,169]}$ as noted early on by Natta. ${ }^{[144]}$ The introduction of polar moieties, such as hydroxy groups, can be expected to further increase the difficulties of metal removal. A resulting poor oxidative stability can be disadvantageous. Low metal contents are also crucial for meaningful biomedical studies and for potential biological applications. Although challenging, this problem can apparently be solved but detailed published data is currently still limited. ${ }^{[170,171]}$

In the aforementioned ROMPS in aqueous emulsion, the synthesis of polymer latices has been mentioned very briefly ties. ROMP of the functionalized monomer 13 by $\mathrm{RuCl}_{3}$ to form stable dispersions of high molecular weight polymer $\left(10^{5} \mathrm{~g} \mathrm{~mol}^{-1}\right.$ versus polystyrene standards) stabilized by a PEO- $b$-PPO- $b$-PEO $(\mathrm{PEO}=$ polyethylene oxide, $\mathrm{PPO}=$ polypropylene oxide) triblock copolymer has been reported by Booth and co-workers. ${ }^{[172]}$ Whereas the monomer is watersoluble, the polymeric product is not, and in this respect the reaction resembles a dispersion polymerization. The stable latices obtained consist of remarkably small particles of $60 \mathrm{~nm}$ diameter, for example. Emulsion polymerization of norbornene by various ruthenium catalysts has recently been investigated in detail by Claverie et al. ${ }^{[173]}$ Using the watersoluble carbene complex 19b or an in situ system $\left[\mathrm{RuCl}_{2}-\right.$ (NaTPPTS $)_{2}$ ]/ethyl diazoacetate as water-soluble catalysts, average activities of up to $10^{4} \mathrm{TOh}^{-1}$ were observed ${ }^{[174]}$ at $80^{\circ} \mathrm{C}$ (for the structure of the water-soluble phosphane NaTPPTS see Section 5). Polynorbornene latices consisting in some cases without further discussion of the latex proper- 
of relatively small particles of generally less than $150 \mathrm{~nm}$ diameter were obtained. The anionic surfactants SDS or Dowfax3B2 $2^{[175]}$ were used, and electrostatically stabilized latices with solids contents of up to $46 \%$ were obtained with the latter surfactant. Unlike typical free-radical emulsion polymerizations, the particle number increases continuously with conversion, thus indicating continuous nucleation. The observed dependence of particle numbers on reaction conditions indicates that homogeneous nucleation occurs, even in the presence of surfactant micelles. To enable utilization of the commercially available hydrophobic carbene complex 18 as a catalyst precursor for latex synthesis, the complex was employed as a solution in toluene/hexadecane miniemulsion droplets (see Section 3). Hereby, in addition to norbornene, cyclooctene and cyclooctadiene, which are unreactive towards the water-soluble catalysts, can be polymerized to latices of high molecular weight polymers. Copolymerization of cyclopentene and cyclooctene by $\mathbf{1 8}$ in miniemulsion has also been reported independently by Kühn et al. ${ }^{[179]}$ Copolymerization of norbornene with poly(ethylene oxide)-substituted norbornene macromonomers by $\mathbf{1 8}$ to afford latex particles has been reported. ${ }^{[176]}$ Although this reaction was carried out in ethanol/dichloromethane mixtures and thus does not represent an aqueous polymerization, from the viewpoint of colloid chemistry it is interesting that the concept of polymerizable stabilizers ("surfmers"), ${ }^{[177]}$ well known from free-radical polymerization, has been applied to a dispersion-type ROMP.

In summary, ruthenium-catalyzed aqueous ROMP has proven to be a versatile method for the preparation of polar substituted polymers. The resulting materials have been utilized for biomedical studies. Utilization of well-defined metal carbenes as initiators enables control over the molecular weight, and water-soluble ruthenium carbenes have recently become available. Monomer/metal ratios on the range of 100/1 have been typically utilized in the polymerization of functionalized norbornenes. Whereas such catalyst or initiator efficiencies are moderate in comparison to other types of aqueous catalytic polymerizations (Sections 2-4), they are certainly satisfactory as a tool for the preparation of special, for example, biologically active, materials. Polymer latices have been prepared successfully by aqueous ROMP, and the particle formation process has been studied recently.

\section{Summary and Outlook}

The principal possibility of aqueous catalytic polymerization of olefinic monomers was demonstrated early on, with pioneering work originating from the 1960s. However, since then significant advances have been achieved only in very recent years: 1) the number of polymers prepared in aqueous catalytic polymerizations has grown substantially; 2) the preparation of stable aqueous polymer latices has been investigated; and 3) strong improvements in catalytic activity have been achieved. High molecular weight polymers ranging from amorphous or semicrystalline hydrocarbons to highly polar water-soluble materials are now accessible. The current state of these developments is summarized in Table 1.

What are the driving factors for these ongoing developments? The discovery of new late transition metal based polymerization catalysts and the availability of well-defined catalyst precursors (not requiring water-sensitive alkylaluminum cocatalysts) has certainly contributed. An increased need for environmentally benign processes in general makes water an attractive reaction medium. With polymer latices, this advantage is not restricted to the polymerization process, but also applies to the product itself. In addition to environmental concerns, water is advantageous as a medium for polymerizations since it enables efficient processes to be achieved. In the context of current general interest in the synthesis and properties of micro- and nanoparticles, it can be noted that catalytic polymerization in aqueous emulsion provides convenient access to dispersions of polymer particles in the size range of about $80 \mathrm{~nm}$ to $1 \mu \mathrm{m}$. Finally, the functional group tolerance of the catalysts has enabled polymerization of special highly polar monomers to afford polymers, for

Table 1. Overview of aqueous catalytic polymerization of olefins.

\begin{tabular}{|c|c|c|c|}
\hline Reaction type & Examples of catalyst precursors used & $\begin{array}{l}\text { Typical activity } \\
\text { reported }\left[\mathrm{TOH}^{-1}\right]^{[\mathrm{a}]}\end{array}$ & Results \\
\hline $\begin{array}{l}\text { alternating olefin - } \mathrm{CO} \\
\text { copolymerization }\end{array}$ & cationic $\mathrm{Pd}^{\mathrm{II}}$ - diphosphane complexes & $6 \times 10^{4}$ & $\begin{array}{l}\text { semicrystalline ethylene-CO copolymers are ac- } \\
\text { cessible with high activities in suspension-type } \\
\text { polymerization. Stable latices of } 1 \text {-olefin copoly- } \\
\text { mers can be obtained }\end{array}$ \\
\hline \multirow[t]{2}{*}{$\begin{array}{l}\text { ethylene and 1-olefin } \\
\text { polymerization }\end{array}$} & neutral $\mathrm{Ni}^{\mathrm{II}}(\mathrm{X} \frown \mathrm{O})$ complexes $(\mathrm{X}=\mathrm{P}, \mathrm{N})$ & $2 \times 10^{5}(\mathrm{Ni})$ & $\begin{array}{l}\text { stable latices of semicrystalline ethylene homo- and } \\
\text { copolymers with high activities }\end{array}$ \\
\hline & cationic $\mathrm{Pd}^{\mathrm{II}}$ - diimine complexes & $10^{3}(\mathrm{Pd})$ & $\begin{array}{l}\text { amorphous highly branched polyethylene in sus- } \\
\text { pension-type polymerization }\end{array}$ \\
\hline butadiene polymerization & $\begin{array}{l}\text { alkylaluminum-activated cobalt catalysts } \\
\text { Rh salts }\end{array}$ & $\begin{array}{l}10^{3}(\mathrm{Co}) \\
2 \times 10^{3}(\mathrm{Rh})\end{array}$ & latices of syndiotactic 1,2-polybutadiene (Co) \\
\hline $\begin{array}{l}\text { vinylic polymerization } \\
\text { of cycloolefins }\end{array}$ & $\mathrm{Pd}^{\mathrm{II}}$ salts & ca. $10^{2}$ & $\begin{array}{l}\text { polymerization of norbornene; polymerization of } \\
\text { polar-functionalized norbornenes }\end{array}$ \\
\hline ROMP & $\mathrm{Ru}$-alkylidene complexes or Ru salts & $\begin{array}{l}10^{4} \text { (norbornene) } \\
10^{2} \text { (functionalized } \\
\text { norbornenes) }\end{array}$ & $\begin{array}{l}\text { living polymerization of polar-functionalized nor- } \\
\text { bornenes. Controlled synthesis of polymers for } \\
\text { biomedical investigations; latices of norbornene } \\
\text { and functionalized derivatives }\end{array}$ \\
\hline
\end{tabular}

[a] The activities have been determined under strongly varying conditions, thus they should only be taken as a measure of the order of magnitude. TO (turnovers): substrate converted [mol] per metal used [mol]. 
example, for biomedical studies. In such small-scale reactions water is a convenient solvent for the polar reactants which enables polymerization in a controlled fashion in homogeneous solution.

What issues can be of interest in the future? As most latices prepared by catalytic polymerization have become available only recently, no data has been published regarding their properties relevant for applications, such as latex stability under different conditions, film formation, and film properties. Co- and terpolymerization of readily available monomers, including polar-functionalized olefins, can be expected to enable control of the latter properties. Particle morphology, for example, the generation of domains of different polarity such as in core-shell particles, represents another interesting aspect. A comprehensive picture remains to be established with regard to the mechanism of particle formation, polymerization kinetics, and, for example, the location of the catalytic centers during the different stages of the reaction (aqueous phase, inside monomer droplets or polymer particles, or on the interface). Further improvements in catalyst performance based on a systematic understanding are certainly also an issue. In a polymerization aimed at preparing a latex, it is desirable to leave the catalyst in the product in order to maintain the intriguing simplicity of this direct route to a polymer dispersion. Thus, catalyst performance must be higher than the levels acceptable in many catalytic synthesis of small molecules $\left(<10^{3} \mathrm{TO}\right)$ where the catalyst is recovered. On the other hand efficiencies must not necessarily compete with Ziegler catalysts or metallocenes $\left(>10^{7} \mathrm{TO}\right)$. Some of the recent discoveries reviewed demonstrate that sufficient catalyst performance can principally be achieved. ${ }^{[178]}$

In summary, recent findings have demonstrated aqueous catalytic polymerizations to be a versatile topic. Various potential applications can be envisioned. Equally, a number of attractive subjects for fundamental research in the areas of colloids science, polymer chemistry, coordination chemistry, and catalysis are evident.

The research of our group referred to in this article was funded by BASFAG and the Deutsche Forschungsgemeinschaft (Sonderforschungsbereich 428 and Graduiertenkolleg "Strukturbildung in Makromolekularen Systemen"). S.M. is also indebted to the Fonds der Chemischen Industrie for financial support. We thank the members of the BASF Dispersions Division for stimulating discussions. Stefan Meier (Freiburg) is acknowledged for contributions to Section 6.

Received: June 11, 2001 [A 476]

[1] Emulsion Polymerization and Emulsion Polymers (Eds.: P. A. Lovell, M. S. El-Aasser), Wiley, Chichester, 1997.

[2] Wäßrige Polymerdispersionen (Ed.: D. Distler), Wiley-VCH, Weinheim, 1999.

[3] Dispersionen und Emulsionen (Eds.: G. Lagaly, O. Schulz, R. Zimehl), Steinkopff, Darmstadt, 1997.

[4] R. M. Fitch, Polymer Colloids: a Comprehensive Introduction, Academic Press, San Diego, 1997.

[5] a) H. U. Petereit, T. Süfke in ref. [2], pp. 277-296; b) ref. [4], pp. $164-172$.

[6] S. Mecking, R. Thomann, Adv. Mater. 2000, 12, 953-956.
[7] A. M. van Herk, K. H. van Streun, J. van Welzen, A. L. German, Br. Polym. J. 1989, 21, 125-132.

[8] H. Turk, W. T. Ford, J. Org. Chem. 1991, 56, 1253-1260.

[9] "Polymer Latices": W. T. Ford, R. D. Badley, R. S. Chandran, S. Hari Babu, M. Hassanein, S. Srinivasan, H. Turk, H. Yu, W. Zhu, ACS Symp. Ser.1992, 492, 423-431.

[10] See, for example, E. Zeller, H. F. Leube, B. Schlarb, H.-J. Kneuper, M. Röper (BASF), EP 810236, 1997 [Chem. Abstr. 1998, 128, $48657 \mathrm{~h}]$.

[11] See, for example, H. F. Leube, J. Schmidt-Thümmes, E. Zeller, H. Maas (BASF), WO 99/28357, 1999 [Chem. Abstr. 1999, 131, 19491f].

[12] Anonymous.

[13] F. de Dardel, T. V. Arden in Ullmann's Encyclopedia of Industrial Chemistry, Vol. A14 (Eds.: B. Elvers, S. Hawkins, M. Ravenscroft, G. Schulz), 5th ed., VCH, Weinheim 1989, pp. 393-459.

[14] In this context it is interesting to note that water-soluble polymers can also be formed as a side product in emulsion polymerization. In the copolymerization of acrylic esters with acrylic acid, water-soluble poly(acrylic acid) homopolymer is also formed, which can function as a steric stabilizer for the latex particles formed.

[15] F. L. Buchholz in Ullmann's Encyclopedia of Industrial Chemistry, Vol. A21 (Eds.: B. Elvers, S. Hawkins, G. Schulz), 5th ed., VCH, Weinheim 1992, pp. $143-156$.

[16] Ziegler Catalysts (Eds.: G. Fink, R. Mülhaupt, H. H. Brintzinger), Springer, Berlin, 1995.

[17] H. H. Brintzinger, D. Fischer, R. Mülhaupt, B. Rieger, R. Waymouth, Angew. Chem. 1995, 107, 1255-1283; Angew. Chem. Int. Ed. Engl. 1995, 34, 1143-1170.

[18] G. J. P. Britovsek, V. C. Gibson, D. F. Wass, Angew. Chem. 1999, 111, 448-468; Angew. Chem. Int. Ed. Engl. 1999, 38, 428-447.

[19] W. Kaminsky, M. Arndt, Adv. Polym. Sci. 1997, 127, 143-187.

[20] W. A. Herrmann in ref. [21], pp. 35-45.

[21] Aqueous-Phase Organometallic Chemistry (Eds.: B. Cornils, W. A. Herrmann), Wiley-VCH, Weinheim, 1998.

[22] a) W. A. Herrmann, W. C. Schattenmann in ref. [21], pp. 447-454; b) R. H. Grubbs, D. M. Lynn in ref. [21], pp. 466-476.

[23] K. Landfester, F. Tiarks, H.-P. Hentze, M. Antonietti, Macromol. Chem. Phys. 2000, 201, 1-5.

[24] J. F. Hyde, J. R. Wehrly (Dow Corning Corp.), US-Pat. 2891920, 1959 [Chem. Abstr. 1959, 53, 19449i].

[25] D. R. Weyenberg, D. E. Findlay, J. Cekada, A. E. Bey, J. Polym. Sci. Part C 1969, 27, 27-34 (ionic ring-opening polymerization of cyclic siloxanes).

[26] C. Maitre, F. Ganachaud, O. Ferreira, J. F. Lutz, Y. Paintoux, P. Hemery, Macromolecules 2000, 33, 7730-7736, and references therein.

[27] K. Satoh, M. Kamigaito, M. Sawamoto, Macromolecules 1999, 32, $3827-3832$.

[28] T. I. Wallow, B. M. Novak, J. Am. Chem. Soc. 1991, 113, $7411-$ 7412.

[29] M. Rehahn, A.-D. Schlüter, G. Wegner, W. J. Feast, Polymer 1989, 30, 1060-1062.

[30] C. Granel, P. Dubois, R. Jerome, P. Teyssie, Macromolecules 1996, 29, $8576-8582$.

[31] S. G. Gaynor, J. Qiu, K. Matyjaszewski, Macromolecules 1998, 31, $5951-5954$.

[32] J. Storsberg, M. Hartenstein, A. H. E. Müller, H. Ritter, Macromol. Rapid Commun. 2000, 21, $1342-1346$.

[33] W. Baidossi, N. Goren, J. Blum, H. Schumann, H. Hemling, J. Mol. Catal. 1993, 85, 153-162.

[34] B. Z. Tang, W. H. Poon, S. M. Leung, W. H. Leung, H. Peng, Macromolecules 1997, 30, 2209-2212.

[35] E. Drent, P. H. M. Budzelaar, Chem. Rev. 1996, 96, 663-681.

[36] A. Sen, Acc. Chem. Res. 1993, 26, 303-310.

[37] A. S. Abu-Surrah, B. Rieger, Top. Catal. 1999, 7, 165-177.

[38] N. Alperowicz, Chem. Week 1995 (July 2), 22.

[39] A. Gray, Chem. Br. 1998 (March), 44-45.

[40] Chem. Eng. News 2000, 78(9), 16.

[41] Technical brochure on Carilon thermoplastic polymers by Shell.

[42] E. Drent (Shell), EP 121965, 1984 [Chem. Abstr. 1985, 102, 46423t].

[43] E. Drent, J. A. M. Van Broekhoven, M. J. Doyle, J. Organomet. Chem. 1991, 417, 235-251. 
[44] E. Drent (Shell), EP 229408, 1986 [Chem. Abstr. 1988, 108, 6617b].

[45] M. Barsacchi, G. Consiglio, L. Medici, G. Petrucci, U. W. Suter, Angew. Chem. 1991, 103, 992-994; Angew. Chem. Int. Ed. 1991, 30, 989-991.

[46] See, for example, J. A. van Doorn, E. Drent, J. J. M. Snel (Shell), EP 280374, 1988 [Chem. Abstr. 1989, 110, 58297h].

[47] J. A. van Doorn, R. L. Wife (Shell), EP 296687, 1988 [Chem. Abstr. 1989, 110, 213629p].

[48] W. Reppe, A. Magin, US-Pat. 2577208, 1951 [Chem. Abstr. 1952, 46, 6143b].

[49] From the data provided in ref. [48], it remains unclear whether true polymers were actually obtained. However, it is evident that at least higher oligomers were formed.

[50] Common monomers used in the reactions of this review have the following water solubilities [mmol L${ }^{-1}$ ] (values at $1 \mathrm{bar}, 25^{\circ} \mathrm{C}$ unless noted otherwise): butadiene $13.6,{ }^{[50 \mathrm{a}]}$ ethylene $4.8,{ }^{[50 \mathrm{a}]} 100$ (40 bar, $\left.25^{\circ} \mathrm{C}\right),{ }^{[68]}$ propylene $4.7,{ }^{[50 \mathrm{a}]}$ carbon monoxide $1.0\left(1 \mathrm{bar}, 20^{\circ} \mathrm{C}\right) \cdot .^{[50 \mathrm{~b}]}$ a) CRC Handbook of Chemistry and Physics (Ed.: D. R. Lide), 80th ed., CRC, Boca Raton, 1999, Chap. 8, pp. $91-101$; b) H. Ledon in Encyclopedia of Industrial Chemistry, Vol. A5 (Ed.: W. Gerhartz), VCH, Weinheim, 1986, pp. 203-216.

[51] Z. Jiang, A. Sen, Macromolecules 1994, 27, 7215-7216.

[52] G. Verspui, G. Papadogianakis, R. A. Sheldon, Chem. Commun. 1998, $401-402$.

[53] G. Verspui, F. Schanssema, R. A. Sheldon, Appl. Catal. 2000, 198, 5 11.

[54] C. Bianchini, H. Man Lee, A. Meli, S. Moneti, V. Patinec, G. Petrucci, F. Vizza, Macromolecules 1999, 32, 3859-3866.

[55] E. Lindner, M. Schmid, J. Wald, J. A. Queisser, M. Geprägs, P. Wegner, C. Nachtigal, J. Organomet. Chem. 2000, 602, 173-187.

[56] G. Verspui, F. Schanssema, R. A. Sheldon, Angew. Chem. 2000, 112, 825-827; Angew. Chem. Int. Ed. 2000, 39, 804-806; see also A. A. Broekhuis, H. Dirkzwager, H. J. Heeres, A. J. van der Linden, W. P. Mul, D. H. L. Pello, S. C. Servaas (Shell), WO 00/68296, 2000 [Chem. Abstr. 2000, 133, 350708c].

[57] M. Schmid, E. Lindner, unpublished results.

[58] A. Held, S. Mecking, M. Schmid, R. Pietruschka, E. Lindner, M. Khanfar, M. Sunjuk, Macromolecules, submitted.

[59] For a related investigation of the Pd-catalyzed reaction of ethylene with $\mathrm{CO}$ to form diethyl ketone, see V. N. Zudin, V. D. Chinakov, V. M. Nekipelov, V. A. Rogov, V. A. Likholobov, Y. I. Yermakov, J. Mol. Catal. 1989, 52, $27-48$.

[60] S. Mecking, Coord. Chem. Rev. 2000, 203, 325-351.

[61] S. D. Ittel, L. K. Johnson, M. Brookhart, Chem. Rev. 2000, 100, 1169-1204.

[62] S. Mecking, Angew. Chem. 2001, 113, 550-557; Angew. Chem. Int. Ed. 2001, 40, 534-540.

[63] H. K. Stryker, G. J. Mantell, A. F. Helin, J. Polymer Sci. Part C 1969, $27,35-48$

[64] L. Wang, R. S. Lu, R. Bau, T. C. Flood, J. Am. Chem. Soc. 1993, 115, $6999-7000$

[65] L. K. Johnson, C. M. Killian, M. Brookhart, J. Am. Chem. Soc. 1995 , 117, 6414-6415.

[66] For a previous observation on a similar behavior of a neutral nickel catalyst in 1-olefin polymerization, see V. M. Moehring, G. Fink, Angew. Chem. 1985, 97, 982-984; Angew. Chem. Int. Ed. Engl. 1985, 24, $1001-1003$.

[67] L. K. Johnson, C. M. Killian, S. D. Arthur, J. Feldman, E. McCord, S. J. McLain, K. A. Kreutzer, M. A. Bennett, E. B. Coughlin, S. D. Ittel, A. Parthasarathy, D. Tempel, M. Brookhart (UNC-Chapel Hill/ DuPont) WO 96/23010, 1996 [Chem. Abstr. 1996, 125, 222773t].

[68] A. Held, S. Mecking, Chem. Eur. J. 2000, 6, 4623-4629.

[69] A. Held, F. Weiss, S. Mecking, Polym. Prepr. 2001, 42, 466-467.

[70] A. Held, Dissertation, Albert-Ludwigs-Universität Freiburg, 2001.

[71] For a discussion of hyperbranched polyolefins, see A. Sunder, J. Heinemann, H. Frey, Chem. Eur. J. 2000, 6, 2499-2506, and references therein.

[72] K. A. Brown, M. R. Kesti, E. Stewart, J. McGrath (3M), WO 97/ 48740, 1997 [Chem. Abstr. 1998, 128, 89246s].

[73] A. Held, F. M. Bauers, S. Mecking, Chem. Commun. 2000, 301-302.

[74] A. Tomov, J.-P. Broyer, R. Spitz, Macromol. Symp. 2000, 150, 5358.
[75] W. Keim, F. H. Kowaldt, R. Goddard, C. Krueger, Angew. Chem 1978, 90, 493; Angew. Chem. Int. Ed. Engl. 1978, 17, 466-467.

[76] K. A. Ostoja-Starzewski, J. Witte, Angew. Chem. 1987, 99, 76-77; Angew. Chem. Int. Ed. Engl. 1987, 26, 63-64.

[77] U. Klabunde, S. D. Ittel, J. Mol. Catal. 1987, 41, 123-134.

[78] K. Kurtev, A. Tomov, J. Mol. Catal. 1994, 88, 141-150.

[79] F. M. Bauers, S. Mecking, Macromolecules 2001, 34, 1165-1171.

[80] S. Mecking, F. M. Bauers, R. Thomann, Polym. Mater. Sci. Eng. 2001, $84,1049-1050$

[81] The polyethylene obtained in aqueous emulsion with complexes $\mathbf{8}$ possesses a very broad molecular weight distribution. Thus, an $M_{\mathrm{w}}$ value of up to $10^{5} \mathrm{~g} \mathrm{~mol}^{-1}$ has been reported; however, $M_{\mathrm{n}}$ values are typically about $10^{3} \mathrm{~g} \mathrm{~mol}^{-1}$ : ref. [74] and A. Tomov, R. Spitz, T. Saudemont, X. Drujon (Elf Atochem), WO 00/20464, 2000 [Chem. Abstr. 2000, 132, 279651a].

[82] In this context, a systematic understanding of the relationship between the catalyst structure and the effect of ethylene concentration on the chain growth rate is of interest. To date, there is no concise picture: a strong dependence of chain growth rate on ethylene concentration has been reported for several neutral nickel catalysts with bidentate ligands (in organic solvents as a reaction medium): a) M. Peuckert, W. Keim, Organometallics 1983, 2, 594 597; b) R. H. Grubbs, presentation at the 219th ACS National Meeting (San Francisco), 2000, paper 230, refs. [77] and [79]. For very similar systems, ${ }^{[84]}$ however, zero-order dependance on ethylene concentration has been found: V. C. Gibson, A. Tomov, Polym Mater. Sci. Eng. 2001, 84, 322-323 and the corresponding presentation at the 221st ACS National Meeting (San Diego), 2001. Similarly, the polymerization of ethylene by cationic $\mathrm{Pd}^{\mathrm{II}}-$ or $\mathrm{Ni}^{\mathrm{II}}-$ diimine complexes investigated by Brookhart and co-workers is zero-order in ethylene, ${ }^{[65]}$ but very similar cationic catalysts with an osazone moiety instead of the aryl-imine function were reported to be first order in ethylene: P. B. Mackenzie, L. S. Moody, C. M. Killian, J. A. Ponasik, G. G. Lavoie, J. C. Pearson, T. W. Smith, L. A. Tucker, M. Moore, A. Farthing, G. King, M. Meadows, C. Sass, E. Savitski, Polym. Mater. Sci. Eng. 2001, 84, 326-327 and corresponding presentation at the 221st ACS National Meeting (San Diego), 2001. It must also be noted that in some aqueous polymerizations local catalyst concentrations (for example, in a droplet) can also be much higher than in traditional polymerization in organic media.

[83] R. Soula, C. Novat, A. Tomov, R. Spitz, J. Claverie, X. Drujon, J. Malinge, T. Saudemont, Macromolecules 2001, 34, $2022-2026$.

[84] Interestingly, the introduction of bulky substituents has also been found to strongly increase catalyst activity and afford low molecular weight polyethylene in non-aqueous polymerizations: V. C. Gibson, A. Tomov, A. J. P. White, D. J. Williams Chem. Commun. 2001, 719720.

[85] L. K. Johnson, A. M. A. Bennett, S. D. Ittel, L. Wang, A. Parthasarathy, E. Hauptman, R. D. Simpson, J. Feldman, E. B. Coughlin (DuPont), WO 98/30609, 1998 [Chem. Abstr. 1998, 129, 149362j].

[86] C. Wang, S. Friedrich, T. R. Younkin, R. T. Li, R. H. Grubbs, D. A. Bansleben, M. W. Day, Organometallics 1998, 17, 3149-3151.

[87] T. R. Younkin, E. F. Connor, J. I. Henderson, S. K. Friedrich, R. H. Grubbs, D. A. Bansleben, Science 2000, 287, 460-462.

[88] F. M. Bauers, S. Mecking, Angew. Chem. 2001, 113, 3112-3115; Angew. Chem. Int. Ed. 2001, 40, 3020-3022.

[89] P. L. Tang, E. D. Sudol, M. E. Adams, C. A. Silebi, M. S. El-Asser, ACS Symp. Ser. 1992, 492, $72-98$.

[90] E. D. Sudol, M. S. El-Asser in ref. [1], pp. 699-722.

[91] K. Landfester, Macromol. Symp. 2000, 150, 171-178.

[92] D. F. Evans, H. Wennerstroem, The Colloidal Domain: where Physics, Chemistry, Biology, and Technology meet, 2nd. edn., $\mathrm{VCH}$, Weinheim, 1999, pp. 66-67.

[93] J. Claverie, R. Spitz, X. Drujon, V. Touchard, M. F. Llauro, R. Soula, Polym. Mater. Sci. Eng. 2001, 84, 329-330 and corresponding presentation by J. Claverie at the 221st ACS National Meeting (San Diego), 2001.

[94] B. Manders, L. Sciandrone, G. Hauck, M. O. Kristen, Angew. Chem. 2001, 113, 4139-4141; Angew. Chem. Int. Ed. 2001, 40, 4006-4007.

[95] The majority of polyolefins are produced with heterogeneous Ziegler catalysts, only a minor portion is produced today with metallocenes. However, for this comparison metallocene catalysts are more suited 
as they are also based on ligand-substituted metal complexes, in contrast to the catalytically active centers of heterogeneous Ziegler catalysts.

[96] R. E. Rinehart, H. P. Smith, H. S. Witt, H. Romeyn, J. Am. Chem. Soc. 1961, 83, $4864-4865$.

[97] A. J. Canale, W. A. Hewett, T. M. Shryne, E. A. Youngman, Chem. Ind. 1962, 1054-1055.

[98] Encyclopedia of Polymer Science and Technology, Vol. 2 (Eds.: H. F. Mark, N. G. Gaylord, N. M. Bikales), Wiley, New York, 1965, p. 709.

[99] R. E. Rinehart, H. P. Smith, H. S. Witt, H. Romeyn, J. Am. Chem. Soc. 1962, 84, $4145-4147$.

[100] M. Morton, B. Das, J. Polym. Sci. Part C 1969, 27, 1-5.

[101] R. E. Rinehart, J. Polym. Sci. Part C 1969, 27, 7-25.

[102] A strong $\mathrm{pH}$ dependence of catalyst activity is generally observed in this rhodium-catalyzed polymerization. Highest activities were observed at $\mathrm{pH} 3 ;{ }^{[97]}$ other authors have used formic acid as a "cocatalyst". ${ }^{[101]}$

[103] P. Teyssie, R. Dauby, Polym. Lett. 1964, 2, 413-416.

[104] A. A. Entezami, R. Mechin, F. Schue, A. Collet, B. Kaempf, Eur. Polym. J. 1977, 13, 193-201.

[105] E. B. Bradford, J. W. Vanderhoff, J. Polym. Sci. Part C 1963, 3, 4164.

[106] R. Taube, G. Sylvester in Applied Homogeneous Catalysis with Organometallic Compounds (Eds.: W. A. Herrmann, B. Cornils), Wiley-VCH, Weinheim, 1996, pp. 280-318.

[107] For example, a comparison of the reaction of [ $\left(\eta^{1}\right.$-allyl $\left.)\left(\mathrm{F}_{5} \mathrm{C}_{6}\right) \mathrm{Pd}(\mathrm{dppe})\right]$ and $\left[\left(\eta^{3}\right.\right.$-allyl $\left.)\left(\mathrm{F}_{5} \mathrm{C}_{6}\right) \mathrm{Pd}\left(\mathrm{PPh}_{3}\right)\right]$ with $\mathrm{HCl}$ to yield propylene shows a strongly decreased susceptibility for protonation of $\eta^{3}$-allyl versus $\eta^{1}-\mathrm{CH}_{2} \mathrm{R}\left(\mathrm{R}=-\mathrm{CH}=\mathrm{CH}_{2}\right)$ by protic reagents: H. Kurosawa, A. Urabe, K. Miki, N. Kasai, Organometallics 1986, 5, 2002-2008.

[108] H. Ashitaka, K. Jinda, H. Ueno, J. Polym. Sci. Polym. Chem. 1983, 21, $1951-1972$.

[109] H. Ashitaka, K. Jinda, H. Ueno, J. Polym. Sci. Polym. Chem. 1983, 21, $1989-1995$.

[110] J. N. Henderson, K. W. Donbar, J. J. Barbour, A. J. Bell (Goodyear), US-Pat. 4429085, 1984 [Chem Abstr. 1984, 100, 157154j].

[111] a) G. L. Burroway (Goodyear), US-Pat. 5278263, 1994 [Chem. Abstr. 1994, 120，218842u]; b) G. L. Burroway, G. F. Magoun, R. N Gujarathi (Goodyear), US-Pat. 5021381, 1991 [Chem. Abstr. 1990, $112,236729 \mathrm{~b}]$

[112] H. Ono, T. Kato, J. Polym. Sci. Part A 2000, 38, 1083-1089.

[113] G. Natta, G. Dall'Asta, G. Motroni, Polym. Lett. 1964, 2, 349-351.

[114] G. Sartori, F. Ciampelli, N. Cameli, Chim. Ind. 1963, 45, $1478-$ 1482.

[115] W. Kaminsky, A. Bark, M. Arndt, Macromol. Symp. 1991, 47, 83 - 93.

[116] U. Peucker, W. Heitz, Macromol. Rapid Commun. 1998, 19, 159162

[117] a) F. P. Alt, W. Heitz, Macromol. Chem. Phys. 1998, 199, 1951-1956; b) B. L. Goodall, L. H. McIntosh, L. F. Rhodes, Macromol. Symp. 1995, 89, 421-432.

[118] B. L. Goodall, D. A. Barnes, G. H. Benedikt, L. H. McIntosch, Proceedings of the 6th International Business Forum on Specialty Polyolefins (SPO'96), Schotland Business Research, 1996, pp. $123-$ 142.

[119] T. J. Deming, B. M. Novak, Macromolecules 1993, 26, $7089-7091$.

[120] G. Schultz, Polym. Lett. 1966, 4, 541-546.

[121] A. Sen, T.-W. Lai, Organometallics 1982, 1, 415-417.

[122] C. Mehler, W. Risse, Macromolecules 1992, 25, 4226-4228.

[123] Review on vinylic polymerization of norborene: C. Janiak, P. G. Lassahn, J. Mol. Catal. A 2001, 166, 193-209.

[124] M. Arndt, M. Gosmann, Polym. Bull. 1998, 41, 433-440.

[125] B. S. Heinz, F. P. Alt, W. Heitz, Macromol. Rapid Commun. 1998, 19, $251-256$.

[126] C. Mast, M. Krieger, K. Dehnicke, A. Greiner, Macromol. Rapid Commun. 1999, 20, 232-235.

[127] R. A. Shick, S. K. Jayaraman, B. L. Goodall, L. F. Rhodes, W. C. McDougall, P. Kohl, S. A. Bidstrup-Allen, P. Chiniwalla, Adv. Microelectron. 1998, 25, 13-14.

[128] N. R. Grove, P. A. Kohl, S. A. Bidstrup-Allen, R. A. Shick, B. L. Goodall, S. Jayaraman, Proc. Int. Conf. Multichip Modules 1997, 6, $224-227$.
[129] For the properties of such polynorbornene and calculations on its structure by various methods see also: T. A. Haselwander, W. Heitz, S. A. Krügel, J. H. Wendorff, Macromol. Chem. Phys. 1996, 197, $3435-3453$.

[130] P. Eychenne, E. Perez, I. Rico, M. Bon, A. Lattes, A. Moisand, Colloid Polym. Sci. 1993, 271, 1049-1054.

[131] L. Puech, E. Perez, I. Rico-Lattes, M. Bon, A. Lattes, New J. Chem. 1997, 21, $1235-1242$.

132] A. L. Safir, B. M. Novak, Macromolecules 1993, 26, 4072-4073.

[133] L. Puech, E. Perez, I. Rico-Lattes, M. Bon, A. Lattes, A. Moisand, New J. Chem. 1997, 21, 1229-1234.

[134] E. Serres, P. Vicendo, E. Perez, T. Noel, I. Rico-Lattes, Langmuir 1999, $15,6956-6960$

[135] J.-H. Lipian, L. F. Rhodes, B. L. Goodall, A. Bell, R. A. Mimna, J. C. Fondran, A. D. Hennis, C. N. Elia, J. D. Polley, A. Sen, J. Saikumar (BFGoodrich), WO 00/20472, 2000 [Chem. Abstr. 2000, 132, 279654d].

[136] C. Pariya, K. N. Jayaprakash, A. Sarkar, Coord. Chem. Rev. 1998 $168,1-48$.

[137] K. J. Ivin, J. C. Mol, Olefin Metathesis and Metathesis Polymerization, Academic Press, San Diego, 1997.

138] J.-L. Hérisson, Y. Chauvin, Makromol. Chem. 1970, 141, 161-76.

[139] For example, poly(norbornene) is used as a synthetic rubber (Norsorex, Zeon Corp.). Amorphous polymers prepared by polymerization of norbornene derivatives (such as dicyclopentadiene) and subsequent hydrogenation of the double bonds are marketed for optical applications (Zeonex, Zeon Corp.). Polycyclooctene is applied as a blend component in rubbers (Vestenamer, Degussa AG). See a) R. Streck in Olefin Metathesis and Polymerization Catalysts (Eds.: Y. Imamoglu, B. Zümreoglu-Karan, A. J. Amass), Kluwer Academic, Dordrecht, 1990, pp. 439-515; b) T. Kohara, Macromol. Symp. 1996, 101, 571-579; c) A. Iio, N. Oshima, Y. Ohira M. Sakamoto, H. Oka (Japan Synthetic Rubber Co), DE 4139476 , 1992 [Chem. Abstr. 1992, 117, 213252e].

[140] R. H. Grubbs, E. Khosravi in Material Science and Technology, Vol. Synthesis of Polymers (Eds.: R. W. Cahn, P. Haasen, E. J. Kramer, A.-D. Schlüter), Wiley-VCH, Weinheim, 1999, pp. 65-104.

[141] T. M. Trnka, R. H. Grubbs, Acc. Chem. Res. 2001, 34, 18-29.

[142] R. R. Schrock, Acc. Chem. Res. 1990, 23, 158-165.

[143] M. R. Buchmeiser, Chem. Rev. 2000, 100, 1565-1604.

[144] G. Natta, G. Dall'Asta, L. Porri, Makromol. Chem. 1965, 81, 253-257.

[145] R. E. Rinehart, H. P. Smith, Polym. Lett. 1965, 3, 1049-1052.

[146] B. M. Novak, R. H. Grubbs, J. Am. Chem. Soc. 1988, 110, $7542-7543$.

[147] W. J. Feast, D. B. Harrison, J. Mol. Catal. 1991, 65, 63-72.

[148] See also: S.-Y. Lu, P. Quayle, F. Heatley, C. Booth, S. G. Yeates, J. C. Padget, Macromolecules 1992, 25, 2692-2697.

[149] W. J. Feast, D. B. Harrison, Polymer 1991, 32, 558-563.

[150] E. Zenkl, F. Stelzer, J. Mol. Catal. 1992, 76, 1-14.

[151] M. A. Hillmyer, C. Lepetit, D. V. McGrath, B. M. Novak, R. H. Grubbs, Macromolecules 1992, 25, 3345-3350.

[152] For polymerization of other, similar functionalized monomers, see S. Y. Lu, J. M. Amass, N. Majid, D. Glennon, A. Byerley, F. Heatley, P. Quayle, C. Booth, Makromol. Chem. Phys. 1994, 195, 1273-1288.

[153] M. B. France, R. H. Grubbs, D. V. McGrath, R. A. Paciello, Macromolecules 1993, 26, 4742-4747.

[154] M. B. France, R. A. Paciello, R. H. Grubbs, Macromolecules 1993 $26,4739-4741$

[155] S. T. Nguyen, L. K. Johnson, R. H. Grubbs, J. W. Ziller, J. Am. Chem. Soc. 1992, 114, 3974-3975.

[156] Convenient routes to the synthesis of the vinyl-substituted ruthenium alkylidenes which offer advantages over the diazoalkane route have also been developed recently: a) T. E. Wilhelm, T. R. Belderrain, S. N. Brown, R. H. Grubbs, Organometallics 1997, 16, 3867-3869; b) J. Wolf, W. Stüer, C. Grünwald, H. Werner, P. Schwab, M. Schulz, Angew. Chem. 1998, 110, 1165-1167; Angew. Chem. Int. Ed. 1998, 37, $1124-1126$.

[157] P. Schwab, M. B. France, J. W. Ziller, R. H. Grubbs, Angew. Chem 1995, 107, 2179-2181; Angew. Chem. Int. Ed. Engl. 1995, 34, 2039 2041. See also: W. A. Herrmann, Angew. Chem. 1978, 90, 855-868; Angew. Chem. Int. Ed. Engl. 1978, 17, 800-813.

[158] D. M. Lynn, S. Kanaoka, R. H. Grubbs, J. Am. Chem. Soc. 1996, 118 , $784-790$. 
[159] a) D. M. Lynn, B. Mohr, R. H. Grubbs, J. Am. Chem. Soc. 1998, 120, 1627-1628; b) D. M. Lynn, B. Mohr, R. H. Grubbs, L. M. Henling, M. W. Day, J. Am. Chem. Soc. 2000, 122, 6601-6609.

[160] S. Wache, W. A. Herrmann, G. Artus, O. Nuyken, D. Wolf, J. Organomet. Chem. 1995, 491, $181-188$.

[161] S. Wache, J. Organomet. Chem. 1995, 494, 235-240.

[162] M. Lautens, A. S. Abd-El-Aziz, J. Reibel, Macromolecules 1989, 22, $4132-4134$.

[163] L. L. Kiessling, L. E. Strong in Topics in Organometallic Chemistry, Vol. 1 (Ed.: A. Fürstner), Springer, Berlin, 1998, pp. 199-231.

[164] K. H. Mortell, M. Gingras, L. L. Kiessling, J. Am. Chem. Soc. 1994, 116, $12053-12054$.

[165] K. H. Mortell, R. V. Weatherman, L. L. Kiessling, J. Am. Chem. Soc. 1996, 118, 2297-2298.

[166] C. Fraser, R. H. Grubbs, Macromolecules 1995, 28, 7248-7255.

[167] M. Kanai, K. H. Mortell, L. L. Kiessling, J. Am. Chem. Soc. 1997, 119, $9931-9932$.

[168] M. C. Schuster, K. H. Mortell, A. D. Hegemann, L. L. Kiessling, J. Mol. Catal. A 1997, 116, 209-216.

[169] A. Mühlebach, P. Bernhard, N. Bühler, T. Karlen, A. Ludi, J. Mol. Catal. 1994, 90, 143-156.

[170] For example, K. Goto, Z. Komiya, N. Yamahara, A. Iio, M. Hisatomi, H. Oka (Japan Synthetic Rubber, Co), US-Pat. 5164469, 1992 [Chem. Abstr. 1989, 111, 175360e].
[171] For the removal of ruthenium from lower molecular weight products of metathesis reactions, see a) H. D. Maynard, R. H. Grubbs, Tetrahedron Lett. 1999, 40, 4137-4140; b) L. A. Paquette, J. D. Schloss, I. Efremov, F. Fabris, F. Gallou, J. Mendez-Andino, J. Yang, Org. Lett. 2000, 2, 1259-1261.

[172] S.-Y. Lu, P. Quayle, C. Booth, S. G. Yeates, J. C. Padget, Polymer Int. 1993, 32, 1-4.

[173] J. P. Claverie, S. Viala, V. Maurel, C. Novat, Macromolecules 2001, 34, $382-388$.

[174] Activity observed in a 15-min experiment; see ref. [173].

[175] Dowfax3B2 is the disodium salt of disulfonated decyl-substituted diphenyloxide (Dow product information).

[176] V. Heroguez, M. Fontanille, Y. Gnanou, Macromol. Symp. 2000, 150, $269-274$.

[177] A. Guyot, K. Tauer, Adv. Polym. Sci. 1994, 111, 43-65.

[178] The closely related issue of catalyst residues in the polymer product has been discussed intensly in the general context of late transition metal catalyzed polymerizations. This awareness is contrasted by little data published regarding, for example, the toxic effects of such residues. The relevance of metal and ligand residues will clearly depend on the application sought and the catalyst used.

[179] I. Kühn, B. Mohr, Y. Durant, P. Schwab, R. Leyrer (BASF), DE 19859191, 2000 [Chem. Abstr. 2000, 133, 74521g]. 